Dossiê "Ser criança no Brasil Hoje: (re)invenções da infância em contexto de mudança social"

\title{
Por que os antropólogos não gostam de crianças? ${ }^{1}$
}

\author{
Lawrence A. Hirschfeld ${ }^{2}$ \\ Tradução de Mauro Marolla Filho ${ }^{3}$ \\ Revisão de Marina Rebeca Saraiva ${ }^{4}$
}

Resumo: Dos principais trabalhos em antropologia, poucos se ocupam especificamente das crianças, o que é uma situação curiosa, uma vez que quase toda a antropologia contemporânea se baseia na premissa de que a cultura é aprendida, não herdada. Embora as crianças tenham uma capacidade notável e indiscutível para o aprendizado em geral, e o da cultura em particular, fato é que a antropologia tem demonstrado pouco interesse nelas e em suas vidas. Este artigo examina os motivos para essa lacuna lamentável e apresenta razões teóricas e empíricas para repudiá-la. Entendemos que a resistência aos estudos da infância é um subproduto de (1) uma visão empobrecida da aprendizagem cultural, que superestima o papel desempenhado pelos adultos e subestima a contribuição das crianças na reprodução cultural e, (2) uma falta de apreciação do alcance e da força da cultura infantil, particularmente na formação da cultura adulta. A proposta deste trabalho é mostrar que a marginalização das crianças e da infância obscureceu nossa compreensão de como as formas culturais surgem e do porque elas são mantidas. Dois estudos de caso, explorando a crença de crianças norte-americanas sobre a contaminação social, ilustram

1 Hirschfeld, L. A. (2002), "Why Don't Anthropologists Like Children?". In: American Anthropologist, 104: 611-627.

2 Professor do Departamento de Antropologia e Psicologia da New School for Social Research e Diretor do Center for Research with Infants and Toddlers.

${ }^{3}$ Cientista da Computação (UFSCar), bacharelando em Ciências Sociais (UFPB), mestrando em Sociologia (PPGS/UFPB) e integrante do Grupo de Estudos e Pesquisas Anarquistas (GEPAN - UFPB).

${ }^{4}$ Doutora em Antropologia Social (USP), pesquisadora filiada ao Grupo de Estudos e Pesquisas em Pedagogias e Culturas Infantis (CEDU-UFAL) e de Etnologia Indígena (ICS-UFAL).

Latitude, Vol. 10, nํㅡㄹ 2, pp. 171-216, 2016

DOI: https://doi.org/10.28998/2179-5428.20160203 
Por que os antropólogos não gostam de crianças?

esses pontos.

Palavras-chave: Antropologia da infância. Cultura infantil. Aquisição de conhecimento cultural. Raça.

A pergunta do título, claro, é só meio séria e claramente incompleta. Meio séria porque os antropólogos, enquanto pessoas, com certeza apreciam a companhia das crianças tanto quanto qualquer outro ser humano. E incompleta, pois, além de chamar a atenção para a marginalização das crianças, também pretendo mostrar que há razões suficientes, e até atraentes, pelas quais as crianças merecem um maior respeito por parte da academia ${ }^{5}$.

Muitos leitores podem argumentar que os antropólogos já têm realizado uma quantidade significativa de pesquisas sobre as crianças, como mostra a vasta literatura que abrange os temas cultura, crianças e infância. Como um observador comentou certa vez, "os antropólogos têm feito tantos estudos sobre as crianças, que já é possível formar uma tradição" (Benthall, 1992:1). Podemos citar alguns exemplos familiares à maioria dos antropólogos: o trabalho de Margaret Mead (1930, 1933); Beatrice e John Whiting (1975; Whiting 1963; Whiting 1941); Brian Sutton-Smith (1959); Mary Ellen Goodman (1970); Helen Schwartzman (1978); John Ogbu (1978); Charles Super e Sara Harkness (1980); Robert LeVine (LeVine et al. 1994); e os antropólogos linguistas Bambi Schieffelin (1990; Schieffelin e Orchs

Agradecimentos. Este artigo foi escrito enquanto eu era membro do Centro de Estudos Avançados em Ciências Comportamentais, Stanford, CA. Reconheço agradecidamente seu apoio generoso. A pesquisa revisada neste artigo teve o investimento do prêmio NSF SBR9319796 e uma subvenção do Gabinete do Vice-Presidente de Pesquisa da Universidade de Michigan. Agradeço a Don Brenneis, Bambi Schieffelin, Ann Stoler, Robert Sussman, Kit Woolard, e vários revisores anônimos por seus comentários das versões anteriores.

${ }^{5}$ Essas reinvindicações deveriam ser duplamente qualificadas. Primeiro, a maioria da antropologia tem mostrado um interesse profissional limitado nas crianças e pouca preocupação em rever isso. Segundo, a construção "maioria da antropologia" se refere a uma estatística, mais do que uma regularidade teórica. Simplesmente quero dizer a maior parte das pesquisas feitas por antropólogos. "Maioria da antropologia" faz pouco sentido se a frase se propõe a selecionar um corpo unido e convergente de teorias. Talvez seja mais próprio o uso de "correntes centrais" em antropologia. 
(1988), e Marjorie Goodwin (1990). ${ }^{6}$ É importante destacar que esses trabalhos não se encaixam em nenhuma corrente tradicional de pesquisas com crianças. Tampouco, como muitos pesquisadores lamentaram (Caputo 1995; Hardman 1973; Schwarz 1981; Stephens 1998; Toren 1993), tiveram sucesso em retirar as crianças da periferia da antropologia.

$\mathrm{Na}$ verdade, a maior parte $\mathrm{da}$ antropologia reconhece (discretamente) que as pesquisas com crianças são um objetivo válido, mas, de um modo geral, é clara a mentalidade de que elas não são importantes. Eu não acredito nisso. Meu objetivo aqui é apontar, questionar e sugerir maneiras de compensar essa negligência. Na primeira sessão deste artigo, faço uma revisão dessa curiosa marginalização, considerando o porquê de ser tão difundida e defendo que há bons motivos para que a pesquisa centrada nas crianças ocupe mais a atenção dos especialistas, bem como a da maioria dos antropólogos. Na segunda sessão, apresento um breve estudo de caso com o qual pretendo mostrar que estudar as crianças, suas formas culturais singulares e sua arquitetura conceitual única traz, paradoxalmente, percepções significativas sobre a natureza da experiência cultural dos próprios adultos. Creio que muitas de nossas crenças culturais permanecem ativas justamente devido à maneira com que a mente das crianças é organizada e pela forma com que elas estruturam seu ambiente cultural. Muitas formas culturais são estáveis e amplamente distribuídas exatamente porque as crianças têm facilidade de pensar sobre elas e de aprendê-las (Sperber, 1996). O desenvolvimento desse argumento oferece uma perspectiva de informação ainda não valorizada sobre a relação entre os fenômenos psicológicos individuais e seu papel na constituição de formas culturais.

\section{1}

A grosso modo, a maior parte da antropologia tem marginalizado as crianças porque desprezou duas características em que elas são muito boas: a capacidade excepcional em adquirir a cultura dos adultos e, de forma menos evidente, o potencial de criar sua própria cultura. Embora não haja dúvidas de que as crianças adquirem os meios para participar das culturas

${ }^{6}$ Meu objetivo aqui não é revisar, mesmo que brevemente, pesquisa antropológica focada em crianças, mas simplesmente mencionar alguns autores cujos trabalhos estariam incluídos na maior parte das listas de antropólogos que trabalharam com crianças. 
Por que os antropólogos não gostam de crianças?

em que habitam, os processos pelos quais isso acontece tem atraído pouca atenção - provavelmente porque a maior parte dos antropólogos considera esses processos banais e pouco informativos para as principais preocupações do campo. As crianças também criam e habitam culturas de sua própria autoria que, de forma significativa, são independentes e distintas daquelas dos adultos com quem convivem. Ao formar suas próprias tradições culturais, as crianças incorporam habilidades conceituais únicas que marcadamente condicionam e moldam suas próprias produções culturais, além daquelas do mundo adulto. Ao enxergar as crianças apenas como receptáculos para a cultura, a antropologia colocou a carroça na frente dos bois. Essa discussão na segunda sessão do artigo será breve e ilustrativa, pois o maior objetivo é demonstrar uma maneira na qual as crianças, suas aquisições e produções culturais podem ser estudadas, ampliando nosso entendimento sobre ambientes culturais de uma maneira mais geral.

Como já mencionado, a indiferença da antropologia para com as crianças não é sentida apenas pela ausência de pesquisas sobre elas, mas, também, pelo pequeno efeito que essas pesquisas têm tido na maior parte da antropologia. De acordo com o Guia AAA 2000 da Associação de Antropologia Americana, entre os dez principais departamentos do Conselho Nacional de Pesquisa, há cento e cinquenta e cinco antropólogos socioculturais pesquisando em tempo integral e, desses, apenas nove (incluindo este autor) declaram possuir interesse em temáticas relacionadas à criança e à juventude. Embora esse nem seja necessariamente o primeiro foco de interesse, pois, entre esses nove acadêmicos, os trabalhos relacionados à infância são, em média, a terceira área de interesse listada. Além disso, quatro dos nove pesquisadores dedicam-se à juventude ou adolescência, uma fase que por definição é fronteiriça.

As publicações seguem e revelam os interesses. Entre 1986 e 2001, de acordo com a base de dados Eureka de revistas revisadas por pares, a "American Anthropologist" publicou três artigos sobre crianças (sem contar as revisões de livros e estudos sobre nutrição). Uma pesquisa por artigos na "American Anthropologist" com os temas "criança(s)", "cuidado infantil" ou "infância" apresentou 14 resultados, desde 1904. Na mesma linha, se os textos introdutórios em antropologia são prenúncio do que está por vir, o futuro não parece muito encorajador. Numa revisão recente em 30 livros-texto bem conhecidos de antropologia, Erika Friedl verificou que, com poucas exceções, as crianças estão subrepresentadas, subteorizadas e 
definitivamente negligenciadas em nossos textos, o que é estranho e desconcertante: "Com poucas exceções, as crianças não só estão subrepresentadas em nossos textos, mas também subteorizadas e definitivamente negligenciadas". (Friedl, 2002:19).

É evidente que nem todo fenômeno interessante necessariamente chama a atenção de todos. Não há uma razão a priori para que a maioria da antropologia deva achar as crianças um tema de pesquisa irresistível. Contudo, existem várias razões substanciais para seu estudo. A mais evidente, é o compromisso da antropologia contemporânea com a ideia de que a cultura é aprendida e não herdada. Embora a aquisição de competências culturais seja um projeto para a vida toda, é notório que as crianças são responsáveis pela maior parte da aprendizagem cultural. $\mathrm{Na}$ adolescência, as crianças de praticamente toda sociedade conhecida apresentam maneiras elaboradas e culturalmente específicas de criar sentido e modos de comportamento claramente bem desenvolvidos. E, embora muitas vezes não sejam consideradas totalmente capazes na adolescência, as crianças são participantes ligadas a uma tradição cultural.

Essa ideia não é um fato latente nem uma dinâmica oculta que deva ser revelada por uma análise minuciosa e sistemática. Praticamente todas as tradições populares reconhecem esse estado de desenvolvimento e muitas o comentam explicitamente. Consideremos, por exemplo, o "custo" da transgressão associado à idade. $\mathrm{O}$ erro das crianças mais novas, sob uma perspectiva cultural, tem um custo relativamente baixo, resultando em uma condenação limitada ou nula (Lancy, 1996). Por outro lado, os erros de desempenho cultural cometidos por pós-adolescentes são geralmente vistos com maior rigor e mais propensos a despertar críticas diretas, punição e outras sanções. A razão para essa diferença de custos é, possivelmente, a convicção de que no desenvolvimento da adolescência, a pessoa deva demonstrar um grau maior de competência cultural, e essa observação não diz respeito a nenhum tipo particular de construção cultural. Independentemente da posição pessoal, seja em uma cultura identificada por suas competências conceituais, por uma gama específica de sentimentos, pelos meios para a produção de desempenho cultural, pela capacidade de estabelecer relações culturais ou pelos processos pelos quais o capital cultural desigual é extraído, é durante a infância que a maior parte dessas conquistas é alcançada. Como boa parte da antropologia se dedica à identificação, compreensão e transmissão do que as pessoas fazem, parece 
Por que os antropólogos não gostam de crianças?

óbvio que pesquisar a maneira como isso se dá poderia ser uma preocupação central do campo. Esse ponto pode ser considerado um imperativo teórico.

Outra razão significativa para se estudar as crianças vem da necessidade do "manejo da coação". Para ilustrar, imaginemos que uma etnógrafa trabalha em meio a uma população cuja estrutura social é altamente estratificada. Um grupo, cuja identidade cultural provém da noção de maturidade e competência, detém um poder significativo sobre uma classe subalterna, cuja identidade deriva da noção de imaturidade e de incompetência. Há relações culturais específicas, de ordem econômica, emocional e social entre os dois grupos e eles se tratam com termos pouco adequados de se traduzir em uma linguagem mais familiar. Existe um intenso contato rotineiro entre esses grupos e um conflito subjacente entre os subalternos e a elite. Embora haja uma superioridade numérica do grupo subalterno, persiste ali um sistema de equilíbrio em que a relação de poder é ativamente administrada, marginalizando sistematicamente esse grupo. Nessa cultura, como em muitas outras, a elite fala sem parar dos subalternos e parece retirar grande parte de sua noção de identidade e competência do seu próprio sucesso, em comparação com o fracasso daqueles. Além disso, a etnógrafa passa grande parte de seu tempo entre os subalternos, observando informalmente suas atividades, a punição pública de suas transgressões e o reconhecimento público de seus méritos. Curiosamente, a etnógrafa não menciona os subalternos em nenhum dos seus textos e raras são as referências às relações econômicas e emocionais que permeiam as interações entre eles e a elite.

Meu ponto aqui é evidente. Tal situação seria vista como fundamentalmente equivocada, já que falhas de observação como essa, quanto às questões de gênero por exemplo, quando efetivamente confrontadas, trouxeram reorientação significativa ao campo. Etnografia e teoria que ignoraram as mulheres foram reconhecidas como empobrecidas e enganosas.

Nossa etnógrafa hipotética, no entanto, pode tentar evitar as críticas argumentando que, diferentemente das noções e das relações de gênero, construídas e dotadas de interessantes variações através das culturas e do tempo, a interação específica elite/subalternos por ela omitida, envolve uma relação de poder, autoridade, economia e sentimento que é universal - $\mathrm{e}$ muitos antropólogos não se sentem compelidos a se deter em domínios de 
experiência que sejam invariáveis. Não é óbvio, contudo, que gênero seja menos um universal e mais uma construção do que a infância. Ambos são universalmente encontrados e ambos formam sistemas de desigualdade, desvantagem e apoio. Tenhamos em mente que um tratamento adequado dado ao estudo de gênero numa cultura envolve mais do que simplesmente reconhecer relações de gênero. Da mesma forma, um tratamento adequado dado ao estudo da infância e das crianças envolve mais que o reconhecimento de que adultos e crianças mantém uma relação particular. "Adicionar crianças e misturar" não é mais inteligente que "adicionar mulheres e misturar". Em ambos os casos, uma genuína mudança no olhar produz uma reconfiguração do campo.

Há ainda um motivo final para se tirar as crianças da periferia, que tem a ver com uma compatibilidade metodológica e teórica. Basicamente, a vida e a experiência das crianças se prestam à investigação antropológica. De forma simplificada, a antropologia é o estudo da natureza e da extensão das diferenças com que populações distintas agem, pensam e falam. O comportamento das crianças, seu pensamento e sua fala são sistematicamente diferentes daquelas dos adultos. As ferramentas de observação e análise que aumentaram o entendimento das especificidades da experiência dos Ashanti e Nuer ou que servem para os gays em São Francisco, ou para os imigrantes que se movem entre o norte da Califórnia e o centro-oeste do México, são também eficazes para o estudo das especificidades da experiência infantil. De fato, recentes mudanças no foco antropológico tornam a investigação sobre a relação entre crianças e adultos ainda mais relevante para a teoria cultural. Subculturas ou culturas assimiladas e suas interações têm praticamente substituído a cultura como objeto da investigação antropológica. As crianças, como discutirei mais detalhadamente a seguir, se constituem em subculturas semiautônomas e, como tal, podem ser utilmente exploradas por antropólogos, assim como os mercadores senegaleses nas ruas de Marselha, os produtores de arroz vietnamitas na Louisiana ou os físicos de alta-energia em Lawrence Livermore. Como a natureza e a prática do poder diário tornam cada vez mais centrais as preocupações dos estudos culturais, as dimensões cotidianas da experiência subalterna que marcam as vidas das crianças também se tornam cada vez mais centrais.

2 Muitas explicações têm sido propostas para justificar a 
Por que os antropólogos não gostam de crianças?

marginalização das crianças. A "culpa" por associação talvez seja a mais comum delas. Comparações inadequadas do pensamento das crianças ocidentais com um pensamento "primitivo" motivou muito da etnologia inicial (ver Levy-Bruhl, 1979) e se manteve por muito tempo (ver Hallpike, 1979), provocando desconforto entre os antropólogos contemporâneos. Mesmo que eles não reconheçam isso, a imagem dessas comparações equivocadas - como aconteceu com as teorias dos estágios da evolução social - pode ter afastado alguns antropólogos do estudo das crianças. Em segundo lugar, as crianças são quase sempre associadas às mulheres e às suas tradicionais esferas de influência - o lar e a alimentação. Como resultado, sugeriu-se que as crianças sofreram a mesma exclusão sistemática do olhar antropológico que suas mães (Caputo, 1995; James e Prout, 1990). Uma apatia latente é outra explicação (embora, é claro, isso seja raramente enquadrado em termos pejorativos). Para a maioria dos antropólogos, a imagem mais comum da criança é a de adultos-em-construção. A liminaridade, ironicamente, fez o interesse antropológico ser mais significativo em outros estágios etários, pois, geralmente se traduz a noção de crianças como seres culturalmente incompetentes que são, naquilo que têm de mais interessante, apenas "apêndices da sociedade adulta" (Bloch, 1991; Caputo, 1995; James and Prout, 1990; Schwartz, 1981; Toren, 1993).

Essas explicações não são plenamente satisfatórias. Assim como o antissemita de Sartre (1948) que, a partir de um encontro desagradável com um alfaiate judeu passou a menosprezar os judeus, mas não os alfaiates, antropólogos incomodados com a comparação inadequada que seus antecessores fizeram do pensamento das crianças como um pensamento primitivo, não abandonaram os estudos sobre as populações nativas, apenas os estudos sobre as crianças. As crianças não foram a única população que sofreu comparações desagradáveis na velha escola. A antropologia do século XIX e início do século XX tinha coisas muito piores para dizer sobre os negros e as mulheres, ainda que isso não tenha levado os antropólogos a excluir raça ou gênero de seus estudos posteriores. "Gênero, raça e classe", enquanto categorias, têm um grande valor no ensino contemporâneo e a atenção dada à forma como elas são construídas e mantidas não são exceções, mas a regra. A virada feminista na antropologia já tem várias décadas e as mulheres e suas vidas estão bem documentadas nos trabalhos antropológicos contemporâneos. Por outro lado, o interesse da maioria dos antropólogos nas crianças continua figuradamente "na infância", para citar 
um trocadilho de Sharon Stephens (1998). Não faz muito sentido achar que as crianças estejam "fora do radar" da antropologia só porque suas mães estiveram. ${ }^{7}$

Essa apatia latente também não se traduz necessariamente em falta de atenção. Mesmo a perspectiva mais "adultocêntrica" não exclui, a priori, o interesse nas crianças. Ao contrário, coloca sobre elas um interesse ainda maior, já que são apêndices da sociedade adulta que frequentemente tornam-se figuras centrais - mesmo que discretamente - tanto nas atividades comuns quanto nas privilegiadas. Os ritos de passagem, a própria lógica das faixas etárias e as noções de descendência e aliança estão conectados com a existência das crianças e dos jovens. Mesmo que as crianças fossem apenas "adultos em construção", isso deveria ser mais uma motivação para o interesse dos antropólogos do que seu afastamento. Crianças são seres cheios de significado em quase todas as sociedades e as atividades específicas sobre seu cuidado e sustento são tradicionalmente reconhecidas e tema comum de discussões. Na verdade, quase todo sistema cultural tem "a criança" como um fato natural, mesmo que variem as particularidades sobre o que a constitui (Ariès, 1962). Noções de "criança", "adulto", "pais" e "descendência" são todas construções culturais e é difícil imaginar conceitos que sejam mais sobrenaturalmente "naturais" no dia-a-dia. Em todo lugar e em todas as épocas, as pessoas têm suas crenças sobre o que são as crianças e o que deveria "ser feito" com elas. Há um enorme interesse nas questões relacionadas com a imaturidade cultural e social daqueles cujas crenças e práticas os antropólogos acompanham de perto. Ao conceber as crianças como meros apêndices da sociedade adulta, a antropologia tem olhado para elas como alguém desprovido de um interesse inerente e isso transfere o problema, não o explica. Ser um apêndice não significa despertar um interesse marginal - um braço é um apêndice, mas não se constitui de um interesse secundário para aqueles que estudam os membros humanos.

7 Um revisor anônimo sugeriu que uma razão para a não emergência de um interesse sério sobre as crianças, diferentemente do interesse sobre 'mulheres' e outros grupos previamente excluídos, é a de que não há antropólogos crianças, portanto, não há uma consistência para buscá-la em seu nome. Isso parece razoável, até certo ponto. A esmagadora maioria dos antropólogos possuem crianças e, dentro de tradição cultural de classe média norte-americana, nossos filhos somos nós. Pergunte à maioria dos norte-americanos de classe média como eles estão e a maioria vai começar a falar de seus filhos. 
Por que os antropólogos não gostam de crianças?

A resistência da antropologia deve estar em outro lugar. A imagem enfraquecida da criança reflete uma ampla tendência da escola norte-americana de ciências sociais em ver a infância como um estágio para o "completo, reconhecido e.... mais significativamente, o desejado" estado adulto (Jenks, 1996:9). Sob esse prisma, as crianças estão destinadas principalmente a se tornarem "com algumas pequenas variações eventuais... o que os mais velhos já são" (Toren, 1993:461). Estudar a mecânica de como isso acontece é da competência dos especialistas. A imagem subjacente é a de que as crianças, especialmente as muito jovens, são radicalmente distintas e desiguais dos adultos à sua volta. Elas estão posicionadas mais na transição para a competência cultural do que tendo domínio genuíno dela. Com isso, discussões sobre crianças quase sempre acabam virando conversas sobre adultos e como eles organizam o ambiente em que as crianças se desenvolvem para facilitar a aquisição da competência cultural apropriada exigida pela sociedade em que vivem. Toren observa com muita perspicácia que, na perspectiva do campo, descobrir como as crianças se tornam "o que os mais velhos já são... [tem] pouco ou nenhum efeito para a análise das relações entre os adultos" (Toren, 1993:461). O conhecimento sobre as relações estáveis entre os adultos e seus filhos fornece pouca ajuda para o entendimento das relações entre adultos, que é o principal fenômeno do interesse antropológico.

A área de pesquisa mais familiar aos antropólogos sobre a vida das crianças é a da socialização, que reflete essa refração da infância pelas lentes adultas. Ao focar no adulto como o estágio final e em sua influência para "chegar lá", as atividades infantis são tidas como acessórias ou subordinadas. Em consequência disso, as contribuições que as crianças fazem para seu próprio desenvolvimento são quase sempre ofuscadas, quando não apagadas. ${ }^{8}$ A rica literatura sobre os jogos e brincadeiras de

8 O rico corpus de trabalho na socialização da linguagem é excepcional a este respeito. Eu não posso avalia-lo de forma abrangente nem mesmo caracterizá-lo adequadamente aqui. Basta dizer que para a presente discussão, a ênfase na pesquisa da socialização da linguagem é em grande parte no treinamento linguístico, em particular, nas formas pelas quais as práticas dos adultos moldam como o jeito cultural e a língua são aprendidos. $\mathrm{O}$ foco é sobre o que os adultos fazem em suas tentativas de garantir que as crianças adquiram conhecimento linguístico apropriado e sensibilidades culturais. Com a exceção de Goodwin (1990), poucos antropólogos têm se preocupado com a forma com que as crianças se tornam 
crianças ilustra bem isso (ver Goldman, 1998; Lancy, 1996; Sutton-Smith, 1976). Fica evidente que esses estudos se voltam para as crianças, particularmente para a rotina e formas culturais que normalmente não possuem um paralelo específico nas atividades dos adultos nem envolvem sua participação direta. As brincadeiras proporcionam uma rica informação sobre as habilidades cognitivas, culturais e sociais das crianças. Apesar dessas percepções, essas pesquisas salientam a relevância das brincadeiras para as atividades e finalidades adultas, especialmente pela maneira com que brincadeiras rotinizadas, incluindo os jogos, servem para aculturar as crianças nas normas e regras do mundo adulto. Lancy (1996) descreve os jogos e brincadeiras como

Artefatos duradouros, parte permanente do repertório das sociedades, reutilizados a cada geração... abrigados... oportunidades de aprendizagem. [Nas brincadeiras] as crianças podem assumir o risco de errar sem consequências mais sérias. Ao mesmo tempo, do ponto de vista que interessa à sociedade, os jogos são dispositivos inteligentes - eles são divertidos... e além disso, seduzem a criança a aprender coisas que a sociedade julga importantes" [LANCY, 1996:94].

A "história dos brinquedos" de Sutton-Smith (1976), por exemplo, é um estudo fascinante de como a produção industrial de brinquedos serviu para levar as crianças a desejarem reproduzir um tipo de existência solitária

socializadas na infância, que, como será sugerido abaixo, é sem dúvida a principal tarefa para a criança encarar. Além disso, a linguística antropológica se manteve praticamente agnóstica no debate sobre se as crianças aprendem a língua em virtude da operação de um dispositivo de aquisição de linguagem nativa ou em virtude de algoritmos de domínio geral para a aquisição de uma ampla gama de conhecimento. Sem dúvida, essa é uma questão crucial sobre a própria contribuição da criança para a aprendizagem de línguas, que será brevemente discutida depois. Dados antropológicos são particularmente relevantes para se estabelecer uma resposta, e o teste mais abrangente da hipótese nativista é um enorme projeto de cruzamento linguístico em que vários linguistas antropológicos participaram (Slobin, 1985). 
Por que os antropólogos não gostam de crianças?

que gera uma forma específica de cidadão burguês.

Não estou criticando esse trabalho - como já disse, um entendimento significativo veio dele e, de fato, ele foi a base da discussão anterior sobre o baixo custo das transgressões infantis. Meu objetivo aqui é mostrar que essa abordagem específica das brincadeiras e dos jogos se alinha com a concepção das crianças e suas atividades como apêndices funcionais da sociedade adulta e de seus objetivos. Ao fazer isso, as atividades das crianças são exploradas apenas dentro dos limites de sua contribuição para as finalidades dos adultos e, mais importante, a "autoria" dos meios de reprodução cultural continua com os adultos. Dessa forma, a teoria da socialização - a ideia de que a disposição dos adultos é alcançada através de intervenções na vida das crianças - obstrui o reconhecimento da contribuição das crianças na aquisição de sensibilidades culturais.

A teoria da socialização infelizmente parece superestimar a influência real que os adultos exercem. Diversos estudos têm mostrado que os adultos frequentemente exercem um modelamento menos significativo sobre a cognição das crianças, suas personalidades e atitudes do que se costuma presumir (Harris, 1998; ver Toren, 1993, para exemplos antropológicos e uma excelente revisão; ver também Hirschfeld, 1989a; Mead, 1932). É difícil compreender como as crianças são excelentes para adquirir cultura e o quanto a "transmissão cultural" é realmente complicada, quando são os adultos que recebem o crédito, excessivamente generoso, por isso. As crianças, de fato, se tornam muito parecidas com os mais velhos quanto ao comportamento crítico, no entanto, há mais coisas envolvidas nisso que apenas sua "socialização" no mundo dos adultos. ${ }^{9}$

${ }^{9}$ Harris (1998) defende que a teoria da realização repousa numa infeliz atribuição de causalidade a um fenômeno de correlação: Pais que "dão bastante amor e aprovação, impõe limites com firmeza, mas com tolerância, não fazem uso de punição física nem tecem comentários cheios de desmerecimento" e Crianças que são "alegres e cooperativas, razoavelmente obedientes... que não sejam negligentes nem muito tímidas, que se dão bem na escola, que têm muitos amigos, e não batem nas outras pessoas sem justa causa" (Harris, 1998:17) são imaginadas como "bons" pais. Ou seja, a forma de ser pai faz a criança vir a ser uma "boa" criança. Isso é tão provável quanto a situação em que crianças cujas personalidades sejam geneticamente consideradas "boas" provoquem em seus pais a realização de uma prática de criação de seus filhos que são compatíveis com a esperada de "bons" pais. Essa alternativa tende e ser desconsiderada pela noção de personalidade 
Quanto à reprodução cultural, essa avaliação excessivamente generosa da socialização não depende apenas do que os pesquisadores buscam, mas, também, de para onde eles olham. É bem aceito que o ambiente adequado para se estudar a aquisição/transmissão cultural é aquele habitado e controlado pelos adultos - estratégia que faz sentido quando os adultos são os principais agentes socializadores. Se são os adultos que criam os mundos culturais nos quais as crianças estão e que controlam a maioria dos processos pelos quais isso acontece, a prioridade do mundo adulto parece consistente. No entanto, se o objetivo é compreender como as crianças contribuem para criar cultura, um foco mais adequado seria o contexto no qual elas fazem a maior parte de sua escolha cultural, que é o da convivência com outras crianças, a chamada "cultura infantil".

A ideia de que as crianças têm suas próprias culturas pode parecer exagerada para alguns leitores. Mas, as crianças podem sentir-se desconfortáveis na cultura adulta e até mesmo ser resistentes a ela, como parece ocorrer muitas vezes nas sociedades norte-americana e do norte da Europa, diante do referencial descritivo que ainda é a tradição cultural dominante. E eis aí o atrito. É um lugar-comum agora a ideia de que os ambientes culturais são múltiplos. $\mathrm{O}$ ambiente cultural que um indivíduo habita pode se tornar fragmentado, fluido, agitado e negociável - seja da perspectiva das informações ou do poder. Todos os ambientes culturais são compostos por ambientes subculturais concorrentes, múltiplos e conflituosos. O reconhecimento de que a cultura infantil é um deles, não deveria apresentar nenhuma dificuldade a priori. Na verdade, para muitos estudiosos isso não é realmente um problema (Corsaro, 1997; Goodwin, 1990; as contribuições de James e Prout, 1990; Maltz e Borker, 1986; Opie e Opie, 1960; ver também Eckert, 1989; Willis, 1981). Obviamente, as crianças não só vivem nas esferas culturais dos adultos com quem partilham suas vidas, mas elas criam e mantém ambientes culturais próprios. Assim, o ambiente cultural em que essa reprodução cultural ocorre não é necessariamente (nem principalmente), aquele relevante para os adultos:

\footnotetext{
"herdada". Ainda assim, há muita pesquisa que apoia a ideia de que dois irmãos são mais propensos a terem personalidades semelhantes do que dois indivíduos escolhidos aleatoriamente (Harris 1998; Plomin e Caspi 1999; Sulloway 1996).
} 
Por que os antropólogos não gostam de crianças?

O objetivo de uma criança não é se tornar um adulto bem-sucedido, assim como o objetivo de um prisioneiro não é se tornar um guarda de sucesso. $\mathrm{O}$ objetivo de uma criança é ser uma criança bem-sucedida.... As crianças não são membros incompetentes da sociedade dos adultos; elas são membros competentes de sua própria sociedade, que tem suas próprias normas e sua própria cultura. Como a cultura dos presos e a cultura dos surdos, a cultura infantil é vagamente baseada na cultura adulta majoritária, dentro da qual existe. Mas, ela se adapta à cultura dominante dos adultos para seus próprios fins, incorporando elementos que estão faltando nessa cultura. [HARRIS, 1998:198-199].

Essas observações vão além do reconhecimento de que nem todas as atividades das crianças se encaixam na sociedade adulta, uma vez que é evidente a participação das crianças em atividades culturais especiais das quais os adultos são efetivamente excluídos. Também é consenso que as crianças desenvolvem e mantêm práticas sociais, redes de relacionamentos e sistemas de significação que são distintos daqueles de seus próprios espaços físicos e sociais. A noção de uma cultura da infância, no entanto, envolve mais do que apenas atividades especiais voltadas para as crianças. Culturas infantis abrangem ambientes substanciais e elaborados que não são apenas distintos, mas também independentes dos ambientes adultos em que estão incorporados. Elas mantêm um rico repertório de jogos e canções - formas culturais - que não parece estar ligado à cultura adulta, formas que "circulam de criança para criança, ultrapassando a influência dos... adultos [que] nada sabem delas... De geração em geração, essa próspera cultura inconsciente permanece despercebida pelo mundo sofisticado [sic] e tão pouco é afetada por ele" (Opie e Opie, 1960:1). Assim que, na construção de seus ambientes culturais, as crianças desenvolvem o mesmo tipo de atividades, estabelecem os mesmos padrões de relações de poder, autoridade e status, e elaboram os mesmos significados que os adultos quando criam e vivenciam seus próprios mundos culturais.

3 
A falta de apreciação dessas elaboradas competências culturais das crianças e a ignorância da riqueza das formas culturais que elas criam e sustentam por si mesmas têm obscurecido o quão importante uma antropologia da infância - para dar um título a esse projeto que estou propondo - poderia ser em qualquer entendimento da reprodução cultural. As teorias de reprodução cultural - o mais correto seria dizer teorias de disrupção da reprodução cultural - são adequadas apenas quando baseadas em uma conta realista das vidas e forças que moldam a vida dos próprios indivíduos que propagam a reprodução. Acredito, no entanto, que a maioria dos antropólogos não está apenas desinformada sobre as crianças, mas demonstram uma aversão duradoura a elas e uma resistência a uma antropologia da infância. E o ponto de tensão para muitos antropólogos, não é simplesmente que as crianças façam mais do que a maioria reconhece, mas que o façam excepcionalmente bem.

Não há dúvidas de que as crianças são geralmente grandes aprendizes e, em particular, estudantes talentosos da cultura. Elas adquirem prontamente as habilidades para se lançarem, sem muitas dificuldades, dentro da vida cultural ao seu redor. Essa fluência perfeita em uma existência cultural específica é resultado de algumas habilidades "profundas". Poucas ficariam satisfeitas com um grau de aquisição cultural baseado em simples mimetismo. As crianças não imitam a cultura, elas a aprendem e a adquirem. Elas representam a informação cultural, manipulam essas informações e as utilizam como base de sentido de mundo e para organizar suas ações dentro dele. Representações, manipulações e computações são ações internas do indivíduo e, portanto, um fenômeno psicológico. A antropologia - incluindo boa parte da antropologia das emoções - vem resistindo a um bom tempo em reconhecer os estados mentais internos e muito menos em explorá-los sistematicamente. Não seria um exagero afirmar que desde Durkheim, a antropologia tem demonstrado aversão a questões psicológicas. (ver Strauss e Quinn, 1997, capítulo 2, para um aprofundamento no tema; ver também Bloch, 1998; Hirschfeld, 2000a; Sperber, 1996).

Elencar a experiência e o desenvolvimento das crianças em termos de fenômenos psicológicos não é o mesmo que afirmar que a cultura é uma ideação ou que pode ser reduzida a isso, ou mesmo que haja algum subconjunto de nosso conhecimento que é especificamente cultural. Isso é sugerir que a participação em determinado ambiente cultural signifique a 
Por que os antropólogos não gostam de crianças?

participação de um conjunto específico de relações cognitivas causais de cuja agência, um corpo de conhecimento é distribuído (Sperber, 1996). É basilar na antropologia, que as formas culturais passam de uma geração a outra por meio da agência de ensino e modelamento, direta e indiretamente. Como observado acima, esse argumento é implicitamente causal - certas rotinas parentais criam as condições para algumas experiências infantis que configuram identidades individuais e coletivas, e isso caracteriza o predomínio das práticas culturais com sua própria reprodução.

Não há dúvida de que a aprendizagem cultural é empiricamente inevitável. Os humanos são, desde o nascimento, seres culturais moldados pelo ambiente cultural no qual vivem. A cultura satura tão completamente o ambiente, que deixar de adquiri-la parece quase impossível. A suposição sutil mais comum é a de que expor um indivíduo a uma multiplicidade de conhecimento cultural faz com que esse adquira uma versão mais ou menos fiel dele. Fica implícita aqui a suposição adicional de que a maior parte do conhecimento cultural é expressa em padrões de comportamento, fala e artefatos que o aprendiz venha eventualmente a reconhecer. Essa consideração é, no mínimo, incompleta, tendo em vista a facilidade que teria o ensino escolar se isso fosse assim. Mesmo se essa teoria de aprendizado fosse aprimorada com algumas restrições (por exemplo, de que o conhecimento é adquirido apenas quando a sua apresentação é clara, informativa e relevante para o aluno - e que este está bem motivado), ela continuaria insuficiente, como bem atestam aqueles que já tentaram ensinar boas maneiras básicas a um adolescente. Simplesmente não existe consideração psicológica plausível que dê conta de explicar como o conhecimento, especialmente o de tipo abstrato, envolvido em esquemas culturais, modelos, símbolos-chave ou regimes de verdade, possa ser adquirido a partir da exposição sem uma considerável mediação por parte do aluno (Hirschfeld, 2001).

Para muitos, isso pode soar como uma afirmação curiosa, afinal, informação cultural e conhecimento cultural podem ser notavelmente extravagantes - eles praticamente saturam o ambiente. É tão confuso quanto óbvio que em cada ato, em cada representação cultural, haja um caráter cultural, uma dimensão cultural que produz uma marca indelével. E parece mais que plausível que as crianças aprendam a ser atores culturais e que elas possam prontamente induzir conhecimento cultural pelo simples fato de viverem em um ambiente culturalmente rico. $\mathrm{O}$ restante está baseado em 
teorias que colocam as culturas como limitadas, relativamente estáveis, em ambientes homogêneos e povoadas com atores que sempre compartilham interesses e conhecimentos. Se as culturas - ambientes culturais - são descontínuas no espaço, fragmentadas, fluídas, contestadoras e estão sempre transformando mundos, como vem sendo dito cada vez mais (Brightman, 1995; Dirks et al., 1994; Gupta e Ferguson, 1997), então, não importa quão marcantes ou culturalmente saturados sejam esses ambientes, aprender sobre eles não é uma tarefa fácil. Aprender "aquele $X$ " quando todos à sua volta dizem $X$, se comportam como se ele fosse verdadeiro e o associam com um valor moral comum, seria presumívelmente mais fácil do que quando $X$ está em debate, altamente contestado e sob situações de desafios morais, políticos e de exclusão. Aprender "aquele $X$ " sob essas condições requer pessoas que tenham significativo talento para identificar as informações do ambiente que sejam relevantes e ignorar as que não.

Os antropólogos nunca deram esse tipo de crédito às crianças - tipo de agência - necessário para executar essa tarefa. Como Hardman (1973) destaca, mesmo os antropólogos interessados nas crianças

Olham para elas, em maior ou menor grau, como objetos passivos, como espectadores impotentes em um ambiente critico que afeta e produz cada um de seus comportamentos. Para eles, a criança está continuamente assimilando, aprendendo e respondendo ao adulto, dotada de pouca autonomia e nada contribuindo para os valores ou comportamentos sociais, exceto nas emanações latentes da experiência anteriormente adquirida (Hardman, 1973:87).

Essa é uma consideração empobrecedora e potencialmente perniciosa do aprendizado cultural (ou aprendizado de forma geral). Ignorar a grande realização que é adquirir conhecimento cultural encoraja os antropólogos a não perceber a contribuição crucial que as crianças dão para a criação, manutenção e distribuição das formas culturais (Sperber e Hirschfeld, 1999). Isso incentiva o campo a ver a aquisição de conhecimento como um processo simples ou, mais precisamente, como um processo simples e direto. Mas, como muitos antropólogos têm observado 
Por que os antropólogos não gostam de crianças?

recentemente, isso não é verdade. (Bloch, 1998; Strauss e Quinn, 1997; Wertsch, 1998).

Adquirir conhecimento cultural é uma realização assimétrica, não porque o perito é um perito e o aprendiz é um aprendiz, mas porque a criança traz consigo habilidades cognitivas especializadas e programas de domínio específico que tornam seu desenvolvimento possível (Hirschfeld e Gelman, 1994). Em certo sentido, o aprendiz é um perito: especialista em aprendizagem. Sem a arquitetura singular da mente das crianças, a cultura seria impossível. Esta afirmação é mais do que um reconhecimento descartável de que os humanos têm mentes individuais e que, portanto, algo interessante poderia ser dito da mente, mas irrelevante para a antropologia. Pretendo fazer uma reinvindicação muito maior, a de que a cultura não pode ser entendida se não for por meio da arquitetura cognitiva das crianças e dos mecanismos especializados em aprendizagem que tal arquitetura proporciona. (Hirschfeld 1996; 1997).

4

Vamos tratar agora de dois casos específicos com os quais quero ilustrar os processos que descrevi: uma tradição cultural infantil específica e uma tradição similar dos adultos, com as susceptibilidades e competências que moldam a relação entre as duas. Ambas são produções culturais da sociedade americana, mas possuem semelhanças com várias outras culturas. As duas formas - a brincadeira da contaminação entre pré-adolescentes e a construção da ideia de raça pelos adultos - certamente parecem desiguais à primeira vista, mas tentarei mostrar que não são. Particularmente, quero analisar como o funcionamento de um programa de aprendizado especializado, implantado no contexto de um ambiente cultural específico, cria as condições pelas quais as crianças montam e mantém um jogo "simples" e como os adultos organizam e mantém um acesso fundamental ao poder, autoridade e recursos. Como já escrevi bastante sobre o pensamento racial (Hirschfeld, 1989a, 1996, 1997, 2000), minha discussão sobre isso aqui será breve. Já o material sobre a brincadeira da contaminação ainda não foi publicado, por isso, vou apresentá-lo de maneira mais detalhada.

Ao longo dos últimos anos, eu e meus colaboradores Susan Gelman, Rachel Heiman, Gail Heyman, Katie Hinds, Barbara Hofer, Oren Kosansky, Ivelisse Martinez e Heidi Schwein-Gruber temos investigado um grande 
conjunto de práticas e crenças das crianças norte-americanas sobre "contaminações" (cooties) (Martinez et al., 1999). Observamos crianças do $2^{\circ}$ e $4^{\circ}$ graus durante suas brincadeiras no recreio, e as entrevistamos em pequenos grupos ou individualmente. Além das crianças do $2^{\circ}$ e $4^{\circ}$ grau, convidamos um grupo do jardim da infância para participar de algumas tarefas experimentais. As crianças foram escolhidas em escolas de diferentes áreas, divididas em dois grupos. Um deles consistiu de escolas nos arredores de Midwestern college town, com crianças predominante brancas e de classe média. O segundo, era composto por escolas que ficavam a oitenta quilômetros de distância, em área predominantemente rural, composta por trabalhadores de pequenas cidades, em que apenas a metade aproximadamente dos estudantes era de pele branca.

Em linhas gerais, as "contaminações" são sujeiras sociais que passam de uma criança a outra, em um tipo de poluição interpessoal. De acordo com uma fonte, o termo "contaminações" (cooties) vem da transformação de uma palavra oriunda das colônias britânicas para "piolho" (lice) que ficou popularizada após o retorno dos veteranos da Primeira Guerra Mundial (Samuelson, 1980). Coerente com essa interpretação, o "The Oxford English Dictionary" define "cootie" como "piolho de corpo" (body louse), que pode ter sido derivada da palavra Malaia "kutu", que significa "inseto parasita que pica". O uso dessa palavra por crianças norte-americanas contemporâneas, por vezes, segue essa definição. Mas, normalmente, as crianças descrevem a "contaminação" como algo que não pode ser visto, mas que é desagradável. Três sinônimos utilizados pelas crianças são os mais comuns para descrever "contaminações": partículas invisíveis associadas a germes, gases intestinais ou "meleca de nariz". Adultos, costumam utilizar tanto contaminações quanto piolhos, provavelmente "relembrando" as memórias de suas próprias infâncias. $\mathrm{O}$ artigo de um certo autor tinha o título "Controle de Piolhos" (Cootie Control), no qual dizia aos pais a melhor forma de tratar infecções de piolhos na cabeça, apesar de não haver menção ao termo “cooties" em seu texto. (Nathanson, 1997).

A maior associação com "contaminações" (cooties), porém, tanto para adultos quanto para as crianças norte-americanas, é a de uma contaminação invisível que passa de uma criança (geralmente aquela de um grupo estigmatizado) para outra e as medidas profiláticas utilizadas para evitá-la. Existem várias medidas preventivas, como antigos catadores de 
Por que os antropólogos não gostam de crianças?

"contaminações", injeções falsas e gestos especiais cruzando os dedos ou as mãos: "se você cruzar suas mãos, não será contaminado"; "se você subir num poste, não será contaminado"; "se você não gosta das pessoas e as tocar, você ficará "contaminado" a menos que cruze seus dedos"; ou "se sua casa estiver contaminada, tranque todas as portas e apague todas as luzes".

Há poucos trabalhos acadêmicos sobre as "contaminações". Dois estudos que se destacam foram realizados por Samuelson (1980) e uma ampla discussão em Brincadeira de Gênero (Gender Play) realizada por Thome (1993). Existem muitas outras abordagens fictícias. Vários romances de autores adultos, alguns dirigidos a adolescentes, mas alguns próprios para o público adulto, usaram as "contaminações" e suas práticas para transmitir uma sensação de mácula social profunda e inseparável, temor e exclusão (Hayter, 1997; Holub, 1998). Mas, em geral, as "contaminações" são uma atividade própria de crianças em idade escolar, executadas, reguladas e experienciadas por elas. Se a cultura das crianças consiste de formas culturais semiautônomas, mantidas pelas práticas infantis, então as "contaminações" (cootie lore) são um verdadeiro exemplo.

As "contaminações" são invisíveis, mas sua prática não é. O cenário paradigmático envolve uma ou várias crianças que transmitem por gestos e outras manifestações de nojo e horror a mensagem de que tiveram contato com as "contaminações" de outra pessoa. A criança poluída pode ser identificada como indivíduo ou, de forma mais típica, como símbolo de uma categoria social: "se uma garota me toca, então eu digo 'eca'"; "se você tocar em alguém, bem, se [você] toca um garoto, garotas não gostam das 'contaminações de meninos' e meninos não querem pegar as 'contaminações de meninas' ... os garotos fogem das garotas".

Essas atividades podem parecer, e por vezes realmente são, como ensaios hiperbólicos, materializados e divertidos das práticas de distanciamento de gênero, comuns entre pré-adolescentes. As "contaminações", no entanto, geralmente são mais graves e, às vezes, a qualidade lúdica do "jogo" não oculta de forma eficiente as emoções mais profundas.

Uma interação ocorrida durante a fase inicial da nossa etnografia colaborativa sobre a cultura das crianças ilustra isso vividamente. Uma das pesquisadoras do projeto, Ivelisse Martinez, testemunhou pessoalmente a força das "contaminações". Ela estava conversando com um grupo de crianças de nove anos em uma sala de aula (o assunto não era sobre 
"contaminações") quando uma garota se aproximou do grupo e se sentou em uma cadeira vazia. Quase imediata e subitamente, ela demonstrou ficar visivelmente chateada. Martinez perguntou-lhe o que havia de errado e ela respondeu, ofegante, que acabara de notar que a criança que estava sentada naquela cadeira antes dela estava "contaminada" (tinha "cooties"). O interessante foi que a atitude da menina não se deu em função da discussão nem foi provocada por ninguém que Martinez tivesse observado. Ela ficou convencida de que a reação da menina não era fingimento nem simulação, mas uma expressão real do medo de ficar contaminada.

Sob um aspecto, o caso foi excepcional. Via de regra, a "contaminação" envolve atribuições de poluição ou do risco de poluição, que surgem quando o contaminador e os potenciais contaminados estão interagindo e as imputações não costumam ser adiadas. Mas, apesar desse aspecto de "tempo-real" da "contaminação", há também um tipo de incerteza sobre ela, pois a criança nunca sabe quando vai ficar "contaminada" nem se poderá ser acusada de "passar" para outros. Diferentemente de outras formas culturais em que ocorre contaminação social - a poluição existente no sistema de castas no sul da Ásia parece um exemplo apropriado para comparar - a "contaminação" (cootie) não é uma ameaça constante para a qual exista uma proteção regular e definida disponível. Tampouco há circunstâncias específicas nas quais a ameaça de "contaminação" esteja sempre presente, seja para um indivíduo ou grupo específico - como ocorre em algumas sociedades quando uma mulher está menstruando. Resumindo, não há contexto específico ou classe de pessoas para as quais ou das quais o risco de "contaminação" esteja invariavelmente presente. Uma mesma pessoa pode estar "contaminada" num dado momento, mas ficar curada logo em seguida. De fato, uma certa "excitação" parece vir dessa falta de previsibilidade da "contaminação".

Dada a associação entre nojo e poluição, não é de admirar que a "contaminação" também sirva como uma "arma, quando uma criança tenta infectar a outra como em um 'pega-pega' de contaminações" (Samuelson, 1980; Thome, 1993). Opie e Opie (1969:75-76) classificam uma variante inglesa ("The Dreaded Lurgi" - O Temido Lurgi) sob a denominação de "toque com efeitos nocivos", na seção de "Jogos de perseguição". Embora as "contaminações" (cooties) sejam geralmente lúdicas e divertidas, elas também podem ser, como visto acima, tanto estratégicas quanto sérias. Elas são frequentemente utilizadas dentro de um esquema cruel e familiar para 
Por que os antropólogos não gostam de crianças?

excluir crianças impopulares, recém-chegadas ou estigmatizadas de outra forma. Os romances que mencionei anteriormente transmitem esse aspecto dramaticamente. No conto infantil "Ivy Green, Rainha da Contaminação" (Ivy Green, Cootie Queen), direcionado a crianças dos primeiros anos escolares, Hollub (1998) conta-se a história de uma jovem garota que ficou marcada por um rumor que circulava entre as garotas "populares" de que ela estava "contaminada". Mais dramático, pelo menos para os adultos, é o conto "A Vingança da Menina Contaminada" (Revenge of the Cootie Girl), no qual Hayter (1997) descreve vividamente o longo trauma social de exclusão de uma garota por ter sido rotulada como "contaminada" na escola primária. A força dessa situação é ressaltada quando ela tenta explica a um amigo japonês, alheio àquela cultura, que uma pessoa "contaminada" é um pária social.

O sentimento de emoção genuína provocado pelas "contaminações" - e a memória persistente delas - ficaram curiosamente explícitas em uma seção do New York Times, durante as primárias das eleições presidenciais de 2000. O artigo, publicado na "Sunday Week" da seção "Review", ilustra a atmosfera de crescente tensão entre dois candidatos Democratas, da seguinte forma: “O vice-presidente referia-se ao Sr. Bradley como seu amigo - pelo menos até a entrevista no "Encontro com a imprensa", quando o Sr. Gore estendeu sua mão... e o Sr. Bradley ficou parado diante dela ela com um olhar que dizia: 'Eca, contaminações'”' (Henneberger, 2000).

A simples menção das "contaminações" (cooties) a meus alunos de graduação desencadeia uma enxurrada de memórias e invariavelmente provoca arrepios coletivos e riso nervosos. Assim como os imigrantes, cujas memórias da infância geralmente são bem nítidas por evocar não só um momento particular de suas vidas, mas também suas experiências culturais e até sensoriais, os adultos norte-americanos têm pouca dificuldade de recuperar instantaneamente as memórias das brincadeiras de "contaminações" e reviver os sentimentos inscritos nelas.

Temos aqui, então, um paradoxo, pois, apesar da força instrumental e da relevância duradoura das "contaminações", as crianças dão respostas surpreendentemente vagas quando questionadas sobre o que realmente são elas, um padrão também reportado por Samuelson (1980). As "contaminações" não são conceitualmente ordenadas. Ao responder nossas questões, uma criança poderia utilizar uma linguagem apropriada para descrever partículas conhecidas, mas invisíveis, como germes ("as 
'contaminações' são como germes, tem germes nelas"; "as 'contaminações' podem te dar germes"; "elas passam maus germes que podem te matar") ou fazer associações com violações de higiene pessoal ("normalmente se um de meus amigos usa o banheiro, eles ficam 'contaminados'” ; "quando alguém cutuca o nariz ou come a melequinha" ; "as 'contaminações' estão onde alguém lambe o assento da cadeira ou come papel" ; "quando você está próximo de alguém que solta 'pum', talvez você possa ficar 'contaminado'”). Em outras ocasiões, as crianças usam uma linguagem mais comum para descrever coisas efêmeras como más associações ou mau comportamento ("se você não gosta de uma pessoa e encosta nela, você pode ficar 'contaminado'; "pessoas 'contaminadas' roubam coisas de outras pessoas, falam muito, brigam e batem nas meninas. Elas são más"; "geralmente você fica 'contaminado' quando alguém faz algo desagradável"). Não raramente, as crianças utilizam descrições misturadas, especialmente quando fazem descrições que ao mesmo tempo implicam em confirmação e descrença nas 'contaminações': "Não creio que sejam reais. Se o fossem, seriam provavelmente muito pequenas e não as veríamos"; “Não gosto delas, pois são apenas uma brincadeira que eu não faço. Eu costumava jogar, mas agora não. Eu realmente não gosto, é nojento ... todo tipo de pessoa pega isso".

Essas declarações vagas e variadas não significam que as "contaminações" sejam inconstantes, mas, sim, desordenadas. Pode-se medir isso pelo grau de distribuição dessa "desordem" no tempo e no espaço. Thome (1993) observa que o mesmo padrão de práticas e crenças é encontrado em comunidades da Califórnia (onde se misturam mexicanos, latinos e europeus), de Michigan e da Costa Leste. Da mesma forma que as entrevistas conduzidas por Samuelson (1980), as nossas revelam considerável consistência entre as reminiscências dos adultos e a prática atual das crianças. Talvez a mais impressionante seja o padrão recorrente nos "jogos" infantis dentro das culturas. Samuelson (1980) reporta versões de "contaminações" na Inglaterra, Espanha, Madagascar e Nova Zelândia. Opie e Opie (1969:75-78) estudaram o jogo britânico "O Temido Lurgi", cujo nome deriva de um programa de rádio da época, ou, curiosamente, de um certo alimento "encontrado" em East Anglia que faria "o preguiçoso" sofrer. Mas, eles perceberam que a forma básica já existia a gerações. O pega-pega Lurgy (grafia de East Anglia) envolve um tipo de pega-pega em que o perseguidor transmite "algo mau ou repugnante" ao tocar a pele do perseguido e, da mesma forma que nas "contaminações", o pega-pega Lurgi 
Por que os antropólogos não gostam de crianças?

nem sempre é só uma brincadeira. Uma diretora de escola, certa vez, contou ter descoberto o jogo quando uma estudante chegou chorando porque "todos diziam que ela tinha 'aquilo'", uma queixa preocupante, relataram os Opies, que foi observada em "várias escolas, grandes e pequenas".

Assim como nas "contaminações", o "Lurgy" faz seleção e enaltece sentimentos negativos em relação a crianças estigmatizadas: "Em Norwich verificamos o uso comum da palavra "lurgy" entre as crianças - "Você é um lurgy" - mas, com um sentido mais restrito de pessoa 'estúpida, boba, pateta, louca [ou] lêndea (filhote de piolho)"'. As mesmas práticas são encontradas pela Grã-Bretanha e "tais brincadeiras parecem ser jogadas por todo o mundo. Em Auckland, Nova Zelândia, quando um garoto é "contaminado" por uma garota, os outros zombam dele, gritando "Você pegou pulga de menina" (Opie e Opie, 1969:77). Os Opies também descrevem formas similares fora do Reino Unido:

Em Valência, um jogo de perseguição bem comum é o "Tu portes la pusa" (Você carrega a pulga). Em Massa, na baía de Nápoles, o jogo é "Peste". E em Madagascar... a criança que fazia a perseguição era boka, um leproso, e quando ele tocava alguém sua lepra era passada para o outro que, por sua vez, teria de se livrar da doença em outra pessoa (OPIE E OPIE,1969:77).

Uma cultura infantil análoga existe no Japão. Engacho são práticas preventivas que as crianças japonesas usam contra um tipo de contágio social que possui uma série de características comuns com as formas abordadas acima. Uma situação típica que levaria ao engacho ocorre quando uma criança está poluída por ter se sujado, por exemplo, com fezes de cachorro (ou alguém que poderia ser estigmatizado por pertencer a uma minoria étnica). A contaminação posterior de outras crianças, no entanto, não se dá pelo contato direto com a substância inicial, mas por causa dela. Assim como nas "contaminações" (cooties) e nas várias outras formas que foram mencionadas, a contaminação social resulta do contato com uma substância invisível, essencialmente abstrata que passa de uma criança a outra. Para prevenir ou remover essa contaminação, se utiliza a prática do "engancho", tipicamente com gestos dos dedos, como nas "contaminações" 
(cootie). Como nos Estados Unidos, autores contemporâneos têm percebido no engacho um meio de os adultos evocarem memórias saudosas da infância. O material apresentado aqui foi fornecido por $\mathrm{Yu}$ Niiya ${ }^{10}$ que, além dos desenhos de sua própria infância, descobriu uma sala de bate-papo na internet dedicada especificamente ao engacho, em que houve uma discussão sobre um filme recente de animação, que ela me relatou por e-mail:

Sen to Chihiro no Kami Kakushi (A Viagem de Chihro) de Hayao Miyazaki, (que) mostrou uma cena de Engacho. Sen (a heroína de 10 anos) vai a uma terra mágica e mata um pequeno monstro do mal pisando nele. Então ela faz dois anéis entrelaçados com os polegares e os indicadores e diz "Engacho! ". O velho homem vê isso e corta o anel com a palma de sua mão, dizendo "Engacho kitta". E Sen finalmente se sente aliviada". [Comunicação pessoal].

O debate começou, aparentemente, durante uma discussão sobre a variação regional da prática de engacho e da possibilidade de que alguns expectadores poderiam não estar familiarizados com isso.

A questão desses vários e variados exemplos não é se as "contaminações", engacho, o Temível Lurgi, etc., são versões um do outro nem se são expressões de algum momento de desenvolvimento universal pelo qual passam as crianças. Mais tarde, quero mostrar que a apreensão dessas formas culturais significa entender aspectos específicos da arquitetura conceitual das crianças. Mas, ainda assim, essas formas culturais são muito indeterminadas por essa arquitetura. Elas são literalmente as estruturas mentais de contato com as representações públicas.

Para a presente discussão, no entanto, o que é relevante é que todos esses "jogos", hábitos, e outras formas culturais que Opie e Opie (1960)

${ }_{10}$ Aprendi sobre 'engacho' através de comunicação pessoal com Yu Niiya e Yuri Miyamoto, participantes de um seminário no Programa de Graduação em Cultura e Cognição, Universidade de Michigan. 'Engacho' veio à tona durante uma discussão sobre contaminações. Sou grato a eles por sua ajuda e particularmente a Yu Niija, por seus esforços em procurar informação adicional e por preparar o relato escrito. 
Por que os antropólogos não gostam de crianças?

chamam de cultura infantil sem autoconsciência, são reproduzidos sem a intervenção de adultos. Retornando ao caso das "contaminações" (cooties), por exemplo, enquanto os adultos criados em uma cultura adequada rapidamente reconhecem e se lembram das "contaminações", as crianças aprendem sobre elas e as vivenciam apenas com outras crianças. Crianças pegam e passam "contaminações" apenas entre si.

A restrição das "contaminações ao espaço conceitual, físico e relacional das crianças cria possibilidades que geralmente permanecem obscuras. Embora as "contaminações" sejam extremamente sugestivas para os adultos, paradoxalmente, eles costumam crer que elas sejam mais uma das muitas atividades triviais das crianças. No entanto, dentro da cultura das crianças, a prática das "contaminações" representa, regula e ordena as relações de poder entre elas. As "contaminações" marcam e policiam distâncias sociais e pessoais e testam as relações de status social e poder através dos riscos de contaminação e reivindicações de impureza. Nesses termos, existem paralelos claros entre as "contaminações" e as várias outras manifestações culturais infantis discutidas antes. Há, também, paralelos evidentes entre formas culturais dos adultos e a contaminação social que regula as relações de poder e autoridade. O sistema de castas no sul da Ásia é um bom exemplo disso e o conceito de raça na sociedade americana também. Embora as "contaminações" falhem quanto à sistematicidade e aparentem independência de contexto, características comuns dos sistemas de pensamento racial e de casta, existem similaridades cruciais quanto a crenças e ao uso delas a serviço de sistemas de poder e autoridade. Repassando esse ponto importante: as "contaminações" estão relacionadas a poder e autoridade dentro da cultura infantil. Elas são utilizadas para estabelecer e manter relações sociais desiguais entre crianças e são, no mínimo, um meio de sinalização e de fazer cumprir tais relações. Como observa Thome (1993): “evitar proximidade física com outra pessoa e seus pertences por eles serem percebidos como [estando contaminados] é uma declaração forte de distanciamento social e alegada superioridade (Thome , 1993:75).

Esse poder deriva de pelo menos dois aspectos da "contaminação": o desordenamento ou a falta de sistematicidade nas atribuições de "contaminação" e a natureza provisória das próprias "contaminações". Elas são tipicamente imprevisíveis, nunca se sabe quando, em que contexto, o porquê ou por quem serão feitas - "elas vêm de diferentes pessoas. 
Qualquer um pode tê-las, mas não sei o que faz você as ter". Em certo sentido, a atribuição de "contaminação" num momento qualquer chama atenção para uma distância social já existente mais do que a cria. ${ }^{11}$

As "contaminações, nesse sentido, funcionam como raça ou casta, e isso provavelmente em virtude de serem atribuídas com uma natureza "natural" única. Um elemento central do pensamento racial e de castas é a diferença naturalizada e seu uso feito para policiar a diferença social. Parte da razão pela qual o contato entre raças ou entre castas é tido como poluente é porque tais contatos supostamente violam ou rompem com uma ordem natural. As crianças, mesmo em idade pré-escolar, compartilham dessas crenças e utilizam razões essencialistas para a diferenciação por raça e casta, esperando que tanto os grupos raciais quanto os de castas se reproduzam de forma semelhante às outras coisas naturais, especialmente as espécies não-humanas. (Hirschfeld, 1996; Mahalingam, 1999; Springer, 1996). Uma explicação possível para a frequente associação de "contaminações" com germes e piolhos é que elas também representam uma imagem naturalizada (distinta de uma natural) do mundo. Ou seja, as "contaminações" evocam a imagem de germes e piolhos não por conta de paralelos empíricos entre eles, mas devido a um paralelo conceitual. Germes e piolhos são um fenômeno biológico ou natural e o paralelo conceitual sugere que a maneira com que os jovens estabelecem e sinalizam o distanciamento social é naturalizada, semelhante à tendência dos adultos de investir aspectos valiosos da sociabilidade de uma maneira natural.

Finalmente, um tipo particular de relação social é policiada e sinalizada por meio das brincadeiras de "contaminação", cuja prática reflete crenças sobre a contaminação de grupo, especialmente em relação ao gênero. (Powlishta, 1995; Thome, 1993). Gênero, no entanto, não é a única relação intergrupos expressa (ou publicamente comentada) por essa brincadeira. Como já foi observado, as "contaminações" frequentemente escolhem pessoas estigmatizadas por causa do seu carácter ou aparência (por exemplo, as crianças que se comportam mal ou que apresentam excesso de peso). Como um garoto comentou sem muita consciência, mas com

11 Outra diferença interessante entre as "contaminações" e aquelas que ocorrem dentro de sistemas de poluição racial e de casta, é que, com a exceção de gênero, as "contaminações" não têm a explícita referência de grupo social que marca o pensamento racial e de casta. Elas tipicamente ligam grupos sociais e poluição por inferência implícita. 
Por que os antropólogos não gostam de crianças?

clareza: "Elas (contaminações) são nojentas, as pessoas correm quando alguém solta um pum ou lambe seus dedos, ou cutucam o nariz e comem 'meleca'. Africanos, Panamenhos. As garotas têm mais que os garotos". (A intersecção das "contaminações", relações intergrupos e preconceito não foi perdida por nenhum dramaturgo (adulto). Em março de 2001, a "San Francisco Bay Area Discovery Museum" apresentou uma peça interativa que pretendia "promover tolerância e diversidade", intitulada "Tiros de 'contaminações': Inoculações teatrais contra a intolerância" (Cootie Shots: Theatrical Inoculations Against Bigotry).

Uma explicação para os paralelos entre "contaminações", raça, casta e gênero de um lado, e germes e piolhos de outro, é que as "contaminações" são uma versão desses outros sistemas de crenças. Elas poderiam simplesmente ser um análogo por transferência das propriedades cuja "base" reside em outro domínio, amplamente estruturado (supostamente) na e pela cultura adulta. Sob esse aspecto, elas poderiam ser uma transferência, até gradual, de relações e justificativas para a forma com que o poder e a autoridade estão distribuídos e regulados na tradição cultural adulta dominante. As "contaminações" podem, ainda, ser uma versão juvenil da cultura dominante, muito próxima do que a teoria de socialização antecipa quanto às formas culturais das crianças serem pontos-de-parada no caminho para a vida adulta.

Para explorar essa possibilidade - e por fim rejeitá-la - precisamos ver quão próximo as "contaminações" e esses outros sistemas de relação estão estruturados. Antes de fazê-lo, no entanto, precisamos descartar uma possibilidade ainda mais simples: as "contaminações" podem ser apenas uma maneira de sinalizar amizade (e a falta dela).

Amizade e Hostilidade: a fim de considerar essa possibilidade, pedimos a um grupo de crianças que imaginassem o seguinte cenário (adaptada de uma atividade de Rozin et al., 1994):

Você está indo para outra escola cantar com sua turma e seu professor lhe pede para pegar uma camiseta do uniforme, que você sabe, é aquela que diz o nome de sua escola e a sua turma. Você precisa pegá-la em uma pilha delas no canto da sala. O professor quer que você se apronte. Você corre, pega uma camiseta, veste e vai se juntar à sua turma. 
Metade das crianças participaram de um cenário positivo:

Pense numa pessoa, uma criança que você conhece e que lhe faria ficar feliz e se sentir bem ao saber que, antes de você, ela vestiu essa mesma camiseta que você escolheu.

Metade das crianças participaram de um cenário negativo:

Pense numa pessoa, uma criança que você conhece e que lhe faria fica infeliz, se sentir mal e chateado se descobrisse que, antes de você, ela vestiu essa mesma camiseta que você escolheu.

Pedimos, então, a cada uma para classificar os motivos apresentados em uma lista que explicassem o seu desconforto (ao descobrir que ela vestiu uma peça de roupa que já tinha sido utilizada por uma outra criança que lhe agradava ou não). Dissemos a elas que a lista de motivos tinha sido preparada a partir das respostas que as crianças de outra escola deram quando participaram do mesmo experimento (a lista foi mesmo elaborada a partir de observações que crianças fizeram durante uma brincadeira não-estruturada que conduzimos durante a fase anterior da pesquisa etnográfica). Cada motivo refletia um de vários modos de contaminação: contaminação por associação ("me fez pensar no quanto não gosto daquela pessoa"), contaminação social ("outras crianças talvez saibam quem a utilizou anteriormente"), ou contaminação devido à uma transferência de partícula ("seriam os germes ou outras coisas pequenas que me fizeram desgostar daquela pessoa"). As crianças classificaram entre contaminação por associação, contaminação social e contaminação devido a características da camiseta como explicações plausíveis, mas, não houve diferenças significativas entre as três opções. A contaminação envolvendo transferência/transmissão de partículas, no entanto, foi classificada como a menos plausível, mas, apenas por coincidência.

Dentro do primeiro conjunto de questões, dissemos a cada participante que as crianças da outra escola mencionavam as "contaminações" (cooties) para explicar o desconforto em utilizar uma 
Por que os antropólogos não gostam de crianças?

camiseta suada de uma criança da qual não gostavam. Dissemos a elas que gostaríamos de aproveitar a oportunidade da entrevista e perguntar o que elas sabiam sobre as "contaminações" ("O que você pode me dizer sobre as 'contaminações'"?). Suas respostas foram agrupadas em grandes categorias.

Em contraste evidente com as justificativas dadas ao desconforto de vestir uma camiseta suada de outra criança, foi mais significativa a probabilidade de as crianças citarem a transferência de partícula/contaminação quando falavam das "contaminações". A maior porcentagem das descrições (31\%), mencionava a transferência de alguma substância (excreção corporal, germes, doença, etc.), 17\% entendiam que era fingimento (é só um jogo), e 11\% percebiam o lado social (categorias sociais ou relacionamento). Assim, ao contrário de suas explicações de "simples" sujeira social - que enfatiza o pensamento associativo e as relações sociais as "contaminações" evocam a percepção de poluição por partículas, conformando um modelo naturalizado.

Estes dados ajudam a situar as "contaminações" no contexto de simples gostos (e desgostos) sociais. Elas podem ser usadas claramente para colocar a atenção sobre crianças desejáveis ou indesejáveis e para testar as noções de distância social e hierarquia. Outros estudos já mostraram que grupos estigmatizados são propensos a ser associados com as "contaminações" (Thome, 1993). Além de pedir às crianças para explicarem sobre seu conforto/desconforto em vestir uma camiseta já utilizada, também pedimos que nos descrevessem como seriam as crianças agradáveis/desagradáveis (sua aparência, se sua família seria parecida ou diferente das delas, se seus pais se chateariam se ela fosse brincar na casa da criança que lhe agrada/não lhe agrada, etc.). As crianças associaram firmemente as ideias de desejabilidade/indesejabilidade a status social, gênero e raça. Elas gostam de ter contato com crianças socialmente parecidas com elas, mas se sentem desconfortáveis, mesmo em um contato indireto, com crianças que se diferenciem delas quanto à raça, classe social e gênero. Existe, no entanto, uma diferença importante entre a simples desejabilidade/indesejabilidade e as "contaminações", uma diferença que indica que as últimas são uma forma cultural característica. As "contaminações" (cooties) estão ligadas à transferência de partículas materiais, embora sejam invisíveis, ao passo que os gostos e desgostos, não.

Germes: essa ideia levanta a possibilidade discutida anteriormente, de que as "contaminações" sejam apenas uma versão de uma crença infantil 
sobre a transferência de outras partículas naturalizadas, os germes. Existem paralelos claros entre a crença infantil sobre as "contaminações" e a crença de adultos e crianças sobre materiais contaminantes. A riqueza das brincadeiras infantis com termos ligados à medicina, como "inoculação das contaminações", "vacina contra contaminação", "spray contra contaminação" e "imunização contra contaminação" (Samuelson, 1980; Thorne, 1993) sugere que crianças ligam conceitualmente os termos "contaminações" (cooties) a germes e infecções e, portanto, podem testar o entendimento das crianças sobre esses fenômenos, como várias das citações anteriores sugerem. Devemos, porém, evitar traçar de forma muito próxima a conexão entre "contaminações" e as formas culturais adultas e os conteúdos médicos. As "contaminações" podem evocar noções de germes e piolhos, mas há diferenças significativas entre elas e o entendimento infantil ingênuo sobre as doenças. Por um lado, como as citações anteriores também mostram, as "contaminações" são consideradas similares a germes ou à crescente susceptibilidade a germes, mas, geralmente, elas não são denominadas assim.

Há outra diferença entre as teorias das crianças sobre as "contaminações" e os germes - notadamente, suas respectivas relações causais com outros eventos da realidade. Enquanto permanecem em aberto as questões sobre qual a melhor forma de interpretar a crença das crianças sobre os germes, há um amplo consenso de que a partir da idade pré-escolar, as crianças entendem que a exposição a germes é geralmente a causa de doenças e seus sintomas (Kalish, 1996; Kister e Patterson, 1980; Siegal, 1988; Sigelman et al., 1993; Solomon e Cassimatis, 1999; Springer e Ruckel, 1992). O modelo mental básico é de causa e efeito: germes causam doenças, como resfriados; piolhos causam desconforto na pele, como coceiras e erupções cutâneas. Crianças pré-escolarizadas também compreendem que partículas invisíveis possuem propriedades causais (ex. açúcar dissolvido em água produz o gosto doce (Au et al., 1993).

Ao contrário dos germes, porém, as crianças não acreditam que as "contaminações" causem algo. Pegar, passar e se livrar delas é central nas "contaminações". Mas, o que acontece materialmente em seguida, não é, como o texto a seguir revela: “Ou alguém pode fazer algo bem nojento. É quando você cutuca seu nariz e depois toca em alguém, aí, você tem de cruzar os dedos". Mas, até crianças pré-escolarizadas entendem que cruzar os dedos não é um modo efetivo de evitar infecções por germes. Ao 
Por que os antropólogos não gostam de crianças?

contrário, a prática das "contaminações" é sobre categorizar e controlar a interação social ("Eles não são legais... se te pegam, eles vão te perseguir se não cruzar as mãos"). Isso é o mesmo que foi descrito por Opie e Opie em Madagascar, em que a criança com "lepra" se livra da doença simplesmente ao tocar em outra criança. Se a crença das crianças sobre as "contaminações" fosse simples reflexo de seu entendimento sobre os germes e outros contaminantes, esperaríamos razoável fidelidade de correspondência entre os modelos mentais de cada fenômeno. Contundo, não há nada na literatura sobre a percepção das crianças sobre os germes que indique uma crença real de que as doenças sejam curadas ao passar as partículas nocivas para outra pessoa.

Raça: Raça é uma força social e, portanto, uma forma cultural, tanto na cultura das crianças quanto na dos adultos. Psicólogos do desenvolvimento (Aboud, 1988; Katz,, 1983) e pesquisadores mais qualitativos (Goodman, 1970), no entanto, têm sustentado por muito tempo a existência de diferenças fundamentais entre a maneira com que as crianças e os adultos compreendem o conceito de raça. Para explorar a relação entre as "contaminações" e os conceitos infantis de raça, precisamos entender a relação entre os conceitos de raça das crianças e dos adultos. Uma descrição básica do pensamento racial "adulto" na América do Norte incluiria estas três proposições populares inter-relacionadas: Primeiro, os seres humanos podem ser exaustivamente segmentados em tipos distintos, de acordo com sua constituição concreta observável ("constituição observável" significa que os tipos raciais são corporificados, naturais e duradouros). Segundo, a participação num tipo em particular carrega consigo qualidades internas e não-óbvias, bem como qualidades externas. Terceiro, a primeira e a segunda proposições estão ligadas por uma teoria causal que postula que indivíduos possuem qualidades tanto observáveis quanto não-observáveis de um tipo racial e particular em virtude de possuir uma essência racial em particular. Essa construção conceitual reflete a contingência da regulação de poder e autoridade, à qual o sistema de pensamento racial serve. Sobre esse argumento, raça trata das relações de poder; poder tem a ver com as relações de agregação estrutural (política, econômica ou cultural) não mentais, consequentemente, o conceito de raça é função de uma relação estruturada existente (ver Hirschfeld, 1996).

Essa consideração não é uma teoria sobre a ontogênese das cognições raciais, mas uma teoria sobre sua construção social. A explicação 
desenvolvimentista amplamente aceita é até mais simples (ver Aboud, 1988; Katz, 1983). As crianças formam categorias raciais ao abrir seus olhos e ver. Uma versão um pouco mais sutil sustentaria que em virtude das contingências de poder e autoridade, os adultos chamam a atenção das crianças para a raça, levando-as a abrir os olhos e a descobrirem. A ideia de que a importância perceptiva da raça contribui para o aprendizado precoce das crianças é consistente com a visão, há muito tempo mantida, de que as crianças são pensadoras concretas, acorrentadas a aparências externas. As crianças pequenas aprendem rapidamente a distinguir a raça de forma muito parecida com a que aprendem sobre outras propriedades humanas mais perceptíveis - ser alto ou loiro, por exemplo. A razão pela qual elas aprendem sobre ser alto, loiro ou negro antes de aprenderem a ser republicanos ou franceses se deve ao fato de que pessoas negras, altas e loiras se destacam mais visualmente que as republicanas ou francesas (Aboud, 1988). A relevância desses elementos perceptivos está por sua vez ligada a uma segunda alegação sobre as propriedades conceituais, de que as crianças não só prestam atenção a diferenças externas, como as interpretam como sendo externas. Em um primeiro momento, para as crianças pequenas, ser negro não se destaca mais que o ser alto, loiro, magro ou ter olhos castanhos. Assim, embora passíveis de formarem categorias raciais, as crianças se sentem seguras com a aparência externa e, quando pensam sobre a ideia de raça, elas a associam com propriedades externas e modificáveis. ${ }^{12}$

Embora essas afirmações tenham ampla aceitação, surpreende que tão poucas pesquisas tenham sido realizadas a fim de testá-las. A ideia de que a cognição racial das crianças é guiada pela percepção é uma suposição

12 Num estudo, Aboud (1988) vestiu crianças brancas com fantasias de esquimó e perguntou se elas eram, então, esquimós. De uma maneira geral elas disseram que "sim". Noutro estudo, Semaj (1980) pintou criancinhas negras de branco com maquiagem e vestiu-as com perucas loiras. Quando perguntadas se eram, então, brancas, elas respondiam que "sim". Ambos os trabalhos admitem múltiplas interpretações. Crianças pequenas poderiam facilmente se confundir sobre a intenção do experimento. Crianças chamam urso de pelúcia de "urso". Elas sabem que os adultos fazem o mesmo. Em vez de confirmarem uma forte crença sobre raça, as crianças do trabalho de Aboud e de Semaj podem simplesmente estar permitindo uma conversa solta. As crianças também podem ter se confundido em como responder às questões sobre a mudança repentina e inventada - de uma criança negra repentinamente parecendo branca. 
Por que os antropólogos não gostam de crianças?

e não a inferência de uma descoberta empírica. Por várias razões - nada excepcionais para os antropólogos - Eu tinha dúvidas quanto a uma interpretação realista de raça, assim, conduzi uma série de estudos a fim de verificar se as crianças realmente tinham seu pensamento baseado em aspectos exteriores. ${ }^{13}$ Diferentemente do senso comum, descobri que o conceito inicial de raça em crianças do norte da Europa utiliza pouquíssimos elementos perceptíveis. A pouca informação visual que havia era tipicamente imprecisa e restrita (Hirschfeld, 1993).

Também realizei vários estudos que exploraram o pensamento das crianças sobre o tema da raça. Em uma pesquisa anterior, chegou-se à conclusão que as crianças pequenas acreditavam que a raça de uma pessoa mudaria se suas aparências exteriores fossem alteradas. Nesse trabalho, pedia-se às crianças para que pensassem sobre mudanças abruptas e incomuns na aparência, para verificar se esse tipo de mudança das tarefas afetava seus julgamentos. Trabalhei com crianças norte-americanas em fase pré-escolar sobre mudanças na aparência com as quais estavam familiarizadas, como crescimento e aspectos familiares. As crianças sabem que à medida que as coisas crescem, sua aparência muda, e também sabem que se parecem com seus pais de alguma maneira, mas não em outras. Usando esse conhecimento como base, pedi que pensassem se certas mudanças eram possíveis. Mesmo crianças de três anos de idade demonstraram entender que a raça de uma pessoa não muda à medida que ela envelhece. Entretanto, contrastando com suas crenças sobre constância racial, as crianças de três anos percebiam que outros aspectos da aparência física, como o tipo físico da pessoa (robusto ou magro), podem mudar durante sua vida. De maneira similar, crianças pequenas acreditam que a criança e seus pais são necessariamente de uma mesma raça, embora não esperem que eles tenham que ter o mesmo tipo físico. ${ }^{14}$

${ }^{13}$ A discussão aqui será limitada aos resultados de trabalhos com crianças sobre grupos raciais, nominalmente, negros e brancos. No entanto, a pesquisa da qual trata esta discussão explorou uma quantidade maior de grupos, compreendendo, dependendo do estudo, hispânicos, asiáticos (do Sudeste) e africanos (do Norte). Resultados indicam que em termos de justificativas descritos aqui, os sistemas de crença das crianças são os mesmos dos agrupamentos de pessoa por cor.

${ }^{14}$ O tipo corporal, a constituição física e a construção do corpo físico foram utilizadas como dimensão de comparação por duas razões. Primeiro, porque é, relativamente estável dentro de um período de vida humano e mesmo entre 
Esses resultados demonstram que as crianças, ao construir e interpretar categorias raciais, extrapolam a visão que receberam, indo bem além da informação dada. Mesmo crianças pequenas têm um entendimento cultural de raça sofisticado e de padrão adulto, favorecendo uma interpretação biológica, abstrata e essencialista, segundo a qual, a raça é conceituada como imutável, ligada ao contexto familiar e que serve para diagnosticar a identidade do grupo. Em suma, mesmo a representação conceitual de crianças pequenas sobre raça é bem similar à dos adultos com os quais convive. Em contraste com pesquisas anteriores, em que as crianças pequenas possuem apenas uma compreensão exterior de raça, esses (e outros) estudos evidenciam a presença de um profundo conceito adulto de raça.

Raça e "contaminações" compartilham de uma característica conceitual singular, uma interpretação naturalizada das diferenças de grupos e uma característica social peculiar: o uso de uma suposta diferença naturalizada para sinalizar e regular diferenças de poder - esta última característica é incontroversa com respeito à raça. Uma visão naturalizada de raça tem sido frequentemente ligada a contingências de poder e autoridade (Guillaumin 1980). As "contaminações", vistas anteriormente, funcionam de maneira similar - embora os efeitos do poder possam parecer sem importância para os adultos, eles não o são para as crianças que o vivenciam (a jaqueta para Ivy Green, a Rainha Piolho pergunta: "A vida de Ivy está arruinada?). As "contaminações", claro, não criam distinções sociais dentro do grupo nem uma prática excludente que faz com que as relações sociais sejam reguladas por elas. O que elas fazem é naturalizar as distinções; dessa forma, as "contaminações" são implantadas na cultura das crianças do mesmo modo com que a ideia de raça é implantada para regular as relações de poder e autoridade na sociedade adulta.

Deixando de lado a comparação de que as "contaminações estão para as crianças" assim como a "raça está para os adultos", as representações sociais e mentais de raça e "contaminações" mudam ao longo da infância. Consideremos a maneira como crianças em fase pré-escolar conceituam os dois grupos sociais. Susan Gelman, Oren Kosansky e eu encontramos que crianças no jardim de infância estão familiarizadas com as "contaminações"

gerações. Segundo, é um índice confiável de conhecimento sobre sua população de origem. 
Por que os antropólogos não gostam de crianças?

e as usam para marcar e regular relações sociais. Já as crianças em fase escolar não esperam que as "contaminações" envolvam a transferência naturalizada de uma substância qualquer. Com relação à raça, ocorre o contrário, as crianças em idade pré-escolar naturalizam o conceito e acreditam que ocorre a transferência de uma essência estranha dos pais para os filhos. No entanto, a raça não regula socialmente as crianças em fase pré-escolar nem criam distâncias sociais, como o que ocorre em crianças um pouco mais velhas. A raça de uma criança não predetermina com quem ela fará amizade. Portanto, embora as "contaminações" e a raça apresentem certa ressonância entre si, elas não seguem o mesmo curso de desenvolvimento nem parecem ser versões uma da outra.

5

O que é então a relação entre essas várias formas culturais e por que estão tão ligadas uma com a outra? A minha explicação é a de que os sistemas de classificação por "contaminações", raça, casta e gênero são todos expressão de um mesmo mecanismo para conceituar diferenças entre grupos humanos. As "contaminações" não são uma forma juvenil, uma versão da cultura das crianças desses outros sistemas sociais de categorização "mais maduros". Todos esses sistemas são produtos de um mesmo impulso conceitual para categorizar, operacionalizados na cultura pré-adolescente norte-americana. Cada um é uma instância independente de uma única dimensão cognitiva no momento em que ela entra em contato com distintas dimensões do ambiente cultural. Um não causa o aparecimento do outro nem fornece um local para a prática de manipulação das relações estruturais próprias do outro. Em vez disso, tudo emerge de uma vontade comum ou disposição cognitiva para imaginar o mundo numa maneira bastante específica.

Já descrevi em outro texto o caráter dessa especificidade. Esses sistemas são produtos de um dispositivo cognitivo que guia o desenvolvimento e a elaboração de tipos humanos (Hirschfeld, 1996). Com isso quero dizer que os humanos são dotados de um dispositivo ou módulo conceitual especificamente dedicado a processar informação e guiar as inferências sobre as coletividades humanas. ${ }^{15}$ Praticamente desde o

15 Esse argumento é detalhado em Hirschfeld (1996), Jackendoff (1992), Furth (1996), e Gigerenzer (1997), que também defende a existência de uma faculdade 
nascimento, as pessoas demonstram a operação desse mecanismo. Bebês fazem distinção entre indivíduos enquanto membros de diferentes gêneros e comunidades linguísticas (Hirschfeld, 1989a; Hirschfeld e Gelman, 1997). Desde a primeira infância, e talvez antes, eles classificam as pessoas, agrupando-as por parentesco, ocupação e raça (Hirschfeld, 1989b, 1996). Além disso, utilizam esses agrupamentos para predizer propriedades não aparentes de seus membros.

A existência de um dispositivo cognitivo ou módulo conceitual para justificar agrupamentos humanos não seria surpreendente. Uma boa parte da atividade humana é regulada e mediada pelas coletividades sociais. Além disso, as coletividades humanas não são facilmente detectáveis como, por exemplo, nos agrupamentos sociais de outras espécies - enxames de abelhas, grandes mamíferos sociáveis que se movem em rebanhos, peixes que se ajuntam em cardumes, aves que migram em bandos - podemos ver tais coletividades. Os grupos sociais humanos raramente se mostram de forma tão evidente e não é de surpreender que os pesquisadores descobrissem que até mesmo os grupos funcionais coletivos são difíceis de detectar perceptivelmente. (Stanton e Morris, 1987). A maior parte de nossa informação sobre grupos sociais é narrativa e não visual, ainda assim, como discutido anteriormente, o entendimento comum é o de que as crianças aprendem sobre eles através do olhar. $O$ resultado é que tanto na antropologia quanto na psicologia, não se considera da forma devida como é difícil adquirir o entendimento culturalmente apropriado dos grupos sociais. (Hirschfeld, 2001).

Ainda assim, é obviamente útil para as pessoas, inclusive para as crianças, saber dos grupos que existem no universo social em que interagem. Uma das maneiras para isso é identificar qual a aparência de seus membros. Da mesma forma que os adultos, as crianças reconhecem que alguns grupos são mais importantes que outros e que uma importância relativa vem do tipo das pessoas ali, de suas supostas naturezas. Uma característica recorrente é a de pensar que algumas maneiras de organizar as pessoas são mais "naturais" que outras, como é o caso do gênero, do grupo de parentesco, da faixa etária, da raça, da casta, etc. Conceitualmente, adultos tendem a naturalizar esses grupos. E é curioso que esses são, também, os primeiros grupos humanos sobre os quais as crianças aprendem

especialmente intencionada que guia o raciocínio social. 
Por que os antropólogos não gostam de crianças?

e que tendem a naturalizar mais facilmente (Hirschfeld, 1988, 1989b, 1995). Obviamente, as crianças devem naturalizar esses grupos simplesmente porque os adultos o fazem. Mas, como tentei mostrar, a evidência do desenvolvimento não oferece suporte para essa conclusão. Ao contrário, as crianças acabam por naturalizar esses grupos por sua própria iniciativa.

Que as crianças o façam por sua própria iniciativa traz consequências importantes também para o entendimento das crenças dos adultos. Entendo que as representações infantis se baseiam em dispositivos cognitivos especializados para guiar o aprendizado sobre grupos sociais. $\mathrm{O}$ dispositivo especializado, no entanto, não só organiza a maneira como as crianças adquirem conhecimento sobre o mundo, mas também organiza a maneira com que os adultos enxergam o mundo social. Eles trazem para seu próprio universo social o tipo de coisa que as crianças têm facilidade de aprender e conservar com o tempo. Essa não é uma necessidade lógica, claro. Os adultos poderiam, e talvez o façam, criar estruturas sociais sem uma analogia com o repertório social infantil. O problema surge ao tentar manter essa construção ao longo do tempo. Quanto mais apreensível for a representação, mais provável que continue a ser aprendida fielmente (isto é, maior a probabilidade de que uma versão fidedigna seja adquirida por mais membros da população) - e a aprendizagem é uma função do pensamento das crianças. Em resumo, a relação epistêmica entre a criança e o adulto, entre a cultura das crianças e a dos adultos é, nesse aspecto, o inverso do conhecimento convencional. As crianças não se tornam o que seus adultos mais velhos são. Ao contrário, os idosos se tornam o que a criança - ou melhor dizendo, o que a arquitetura da mente da criança - concebe (ver Sperber, 1996, sobre a teoria da comunicação e a epistemologia da representação, bases desse argumento).

Gênero, parentesco, idade, raça, casta e outros agrupamentos naturalizados estão entre as entidades sociais mais precocemente adquiridas. Eles são também os agrupamentos sociais mais intimamente ligados à distribuição de poder e de autoridade, e isso não é uma coincidência. De acordo com o conhecimento comum, as crianças acabam por naturalizar esses grupos devido à política econômica relevante que elas têm na sociedade (adulta) em geral. Ou seja, segundo o entendimento comum, são as categorias que primeiramente emergem, pois são socialmente muito relevantes. Há um aspecto intrincado nessa consideração, pois a noção de que tais categorias são socialmente relevantes 
coincide com a noção de que gênero, parentesco, idade, raça e outros agrupamentos naturalizados são aprendidos primeiro por causa de suas marcantes correlações exteriores e, que eu saiba, ninguém levou isso em conta. ${ }^{16}$ Por isso, como discutido anteriormente, as crianças aprendem a reconhecer essas categorias pois elas são fisicamente muito evidentes, e a ideia de que essas categorias emergem tão cedo por conta da evidência perceptiva é um engano.

A raça é importante para a organização do poder e da autoridade por causa de uma propensão que as crianças têm de naturalizar esse tipo de categoria. Um mecanismo especializado de aprendizado que torna a naturalização social uma "conquista" simples, por fazer a naturalização facilmente racional, é a precondição para esses processos de distorção, explicação e justificação ideológicas. Em um sentido crítico, o poder é racial pois as crianças consideram que naturalizar os grupos sociais é cognitivamente fácil. Ao menos no caso da raça, o fato de que o conceito desempenha um papel fundamental na organização do poder e da autoridade na sociedade, não é a causa de suas propriedades cognitivas, mas deriva delas. Políticas raciais se sustentam não porque simplesmente servem e definem as relações de poder e autoridade, mas porque as crianças as tornam fáceis de pensar (ver Hirschfeld, 1997, para uma discussão detalhada desse argumento).

É importante reforçar esse ponto. Não estou sugerindo que raça é um conceito inato ou que as crianças devam adquirir tal conceito sem o suporte de um ambiente cultural. Raça não é um conceito inato. De fato, dado que é historicamente um conceito relativamente recente, é difícil ver como poderia sê-lo. Na ausência de um ambiente cultural no qual a raça é uma dimensão fundamental de organização política, econômica e cultural, as crianças não a aprenderiam. Isso pode começar a parecer com a visão que estou questionando, pois dá a impressão de que estou atribuindo à

16 Parentes não são sempre nem claramente parecidos exteriormente. No entanto, a maior parte dos relatos sobre o desenvolvimento de categorias de parentesco presumem que o significado genealógico do parentesco ("real") é antecipado em seu desenvolvimento por uma representação que foca nos correlatos percebidos de sua referência (ex., a avó significa "mulher velha, com cabelo cinza e óculos bifocais"), ou que o significado é subordinado a algum aspecto social de distinção (ex., a identificação de parentesco com residência compartilhada). Ver Hirschfeld, 1989b, para uma crítica sobre ambas as reinvindicações. 
Por que os antropólogos não gostam de crianças?

aquisição precoce da raça o papel central na organização da sociedade. Não é esse meu objetivo. Existem muitas maneiras de organizar a vida política, econômica e cultural e, sem dúvidas, muitas já foram implementadas. A questão é: quantas ainda permanecem conosco? Bem poucas. Raça, ao que parece, é uma dessas que têm conseguido ficar. Outros princípios de organização não passaram no teste do tempo. Outros que se mantém, como classe ou nacionalidade, são indiscutivelmente melhor interpretadas como versões (ou derivações) do pensamento racial (Stoler, 1995). De fato, argumenta-se, e acredito que corretamente, que a raça é um princípio de organização menos central da sociedade norte-americana que uma distorção sistemática dessa organização (Wlnant, 1994).

Entendo que a raça se tornou tão generalizada por ser muito fácil de se aprender. Das várias dimensões em torno das quais a vida político-econômica e cultural pode ser e tem sido organizada (ou que ao menos parece ser organizada), a ideia de raça tem tido "êxito" porque é muito fácil compreendê-la. Essa facilidade se deve às relações dessa ideia com um programa especial de aprendizado sobre entidades sociais. Especificamente, a ideia cultural de raça encontra as condições de entrada dispara a operação - de um módulo especializado em criar tipos humanos e, portanto, é prontamente estabilizada e enraizada num ambiente cultural. O módulo de tipos humanos é um dispositivo de desenvolvimento, um mecanismo para guiar a aquisição de conhecimento ${ }^{17}$. A ideia de raça continua sendo parte do ambiente cultural, e assim, uma dimensão do ambiente no qual as crianças fazem uma "amostragem" em seus primeiros mapeamentos do mundo social, pois "raça" se "encaixa" bem na arquitetura conceitual que guia as visões das crianças sobre o desenvolvimento do mundo. Dessa forma, a criança é o pai do homem (desculpem-me pela simplificação do gênero). ${ }^{18}$

17 É certo que o módulo especializado evoluiu em um ambiente em que ainda não existia a noção de raça. No entanto, módulos especializados moldam o pensamento contemporâneo, apesar do fato de que os eventos contemporâneos, reunindo suas condições de entrada, não existiam durante o período em que eles evoluíram. Máscaras e pintura faciais são formas culturais comuns, porque elas encontram (ou seja, disparam) os módulos especializados para reconhecimento de face, que evoluíram como técnicas para o rastreamento e individualização das pessoas (Sperber, 1996).

${ }^{18}$ Raça não é o único exemplo de constituição infantil de crença adulta. Maltz e 


\section{CONCLUSÃO}

Vale a pena repetir quão curiosa é a aversão da antropologia para com as crianças. Certamente que os antropólogos têm muitas oportunidades para encontrar, falar e observar as crianças. Mais importante, as crianças são fundamentais teoricamente, já que a antropologia tem como premissa um processo em que o desempenho das crianças é melhor que o de todos os outros: a aquisição de conhecimento cultural. E o alerta para inserir a antropologia das crianças nas principais pesquisas tem sido feito repetidamente, entre outros, por Hardman, (1973); Schwartz, (1981); Toren, (1993); Caputo, (1995) e Stephens,(1998). E até agora, um programa de pesquisa focado nas crianças que seja sólido, coerente e - mais crítico teoricamente influente, ainda não emergiu. Ao invés de repetir, mais uma vez, a mesma queixa, tentei demonstrar nesse ensaio a relevância teórica que um entendimento refinado sobre a aquisição de conhecimento proporciona. Indivíduos habitando ambientes culturais particulares parecem manter versões relativamente fiéis do conhecimento cultural de cada um. ${ }^{19}$ Enquanto os antropólogos vinham tentando explicar isso, eles

Borker (1986) descrevem um processo similar com as relações de poder e gênero:

O processo de aquisição de um discurso específico de gênero e padrões de comportamento por crianças em idade escolar, é mais complexo do que simplesmente copiar o "generaleto" dos adultos... Entre as crianças em idade escolar, padrões de interação social amigável são aprendidos não tanto dos adultos, mas, sim, por membros de seu grupo de pares... Nossa análise sugere uma maneira diferente de pensar a conexão entre o comportamento relativo ao gênero de crianças e de adultos. A maior parte das discussões sobre o papel da sexualidade na socialização foi baseada na premissa de que as diferenças de gênero são maiores para adultos e que essa referência adulta é aprendida gradualmente ao longo da infância. Nossa análise, por outro lado, sugere que ao menos alguns aspectos do comportamento estão mais fortemente diferenciados pelo gênero durante a infância e que padrões adultos de amizade, por exemplo, envolvem um aprendizado para superar, pelo menos parcialmente, alguns padrões culturais específicos do gênero, típicos da infância. [MALTZ e BORKER, 1986:215].

19 Isso não deve se confundido com a alegação de que as pessoas acreditam nas mesmas coisas, um exagero sobre compartilhamento no qual a antropologia está bem distante. As pessoas podem ter representações semelhantes em suas cabeças sem ter as mesmas atitudes sobre tais representações. Posso estar ciente de que nos Estados Unidos, as mulheres são consideradas más motoristas, mas posso não acreditar nisso. 
Por que os antropólogos não gostam de crianças?

assumiram um padrão bastante simples de instrução antiga do aprendizado dos alunos - seja diretamente, através da instrução, ou indiretamente, através do modelamento. A ideia contrária de que os mais velhos podem se comportar e acreditar da maneira que fazem por causa das ações de seus filhos, tem pouco valor na antropologia, embora haja, como tentei mostrar, uma considerável quantidade de evidências de que isso ocorra. Não estou afirmando que crianças moldam o comportamento dos adultos e suas crenças como uma regra geral. Uma problematização interessante é determinar com que frequência isso ocorre e em que contextos. Mas, independentemente da resposta, deveria estar claro que a importância e relevância dela é maior que o interesse demonstrado pelos antropólogos.

As questões que enfatizei aqui dizem respeito a um fenômeno mais geral: $\mathrm{O}$ que faz alguma coisa ser cultural? Entender como as coisas se tornam culturais requer que entendamos como as crianças processam as informações. Como observou Sperber (1996:54), explicar a cultura "é explicar porque algumas representações se tornam amplamente distribuídas e explicar porque algumas representações obtêm mais sucesso -maior contágio - que outras". Além do que mais puderem ser, boas ideias são geralmente altamente apreensíveis. Se as crianças não puderem representar ideias através de um estímulo disponível, é bem provável que essas ideias só continuem ativas a um custo muito elevado. ${ }^{20}$ Aprender não é simples - ou irrelevante - como uma boa parte da antropologia pensa, principalmente porque a mente - sua arquitetura, as maneiras como ela forma e usa as representações, sua história natural - não é tão simples como a antropologia tem considerado. Antropólogos podem não gostar das crianças, mas deveriam.

\section{Referências bibliográficas}

20 Para maior precisão, "crianças" deveria ser substituído por "aprendiz", na sentença anterior. As crianças podem não achar novas teorias em astrofísica, mas essas teorias ainda assim são formas culturais. No entanto, se aprendizes de astrofísica não puderem aprender essas teorias, elas não serão aculturadas, no sentido de que não encontrarão suporte ou ampla distribuição dentro da cultura dos astrofísicos. 
ABOUD, Frances E. Children and Prejudice. New York: B. Blackwell, 1988. ARIES, Philippe. Centuries of Childhood; a Social History of Family life. New York: Knopf, 1962.

AU, T., SIDLE A., and ROLLINS K. Developing an Intuitive Understanding of Conservation and Contamination: Invisible Particles as a Plausible Mechanism. Developmental Psychology 29:286-299, 1993.

BENTHALL, Jonathan. A Late Developer? The Ethnography of Children. Anthropology Today 8(2): 1, 1992.

26:183-198, 1991. Language, Anthropology and Cognitive Science. Man

BLOCH, Maurice. How We Think They Think: Anthropological Approaches to Cognition, Memory, and Literacy. Boulder: Westview Press, 1998.

BRIGHTMAN, Robert. Forget Culture: Replacement, Transcendence. Reflexification. Cultural Anthropology 10:509-546, 1995.

CAPUTO, Virginia. Anthropology's Silent "Others": a Consideration of Some Conceptual and Methodological Issues for the Study of Youth and Children's Cultures. In: Youth Cultures: A Cross-Cultural Perspective. TALAI, V. A. and WULFF, H. eds. Pp-19-42. New York: Routledge, 1995.

CORSARO, William A. The Sociology of Childhood. Thousand Oaks. CA: Pine Forge Press, 1997.

DIRKS, Nicholas B., ELEY, Geoff and ORTNER, Sherry B. eds.. Culture/Power/History a Reader. In: Contemporary Social Theory. Princeton: Princeton University Press, 1994

FURTH, Hans Desire for Society: Children's Knowledge as Social Imagination. New York: Plenum Press, 1996.

GIGERENZER, Gerd The Modularity of Social Intellixencf. In Machiavellian Intelligence II: Extensions and Evaluations. Andrew Whiten and Richard Byrne, eds. Pp. 264-288. New York: Cambridge University Press, 1997.

GOLDMAN, L. R. Child's Play: Myth, Mimesis, and Make-Believe. Oxford: Berg, 1998.

GOODWIN, M. He-Said-She-Said: Talk as Social Organization among Black Children. Bloomington: Indiana University Press, 1990.

GUILLAUMIN, Claudette The Idea of Race and Its Elevation to Autonomous Scientific and Legal Status. In Sociological Theories: Race and Colonialism. Paris: Unesco, 1980.

HARDMAN, C. Can There Be an Anthropology of Children? Journal of the 
Por que os antropólogos não gostam de crianças?

Anthropological Society of Oxford 4(1):85-99, 1973.

HARRIS, Judith R. The Nurture Assumption: Why Children Turn out the Way They Do. New York: Free Press, 1998.

HAYTER, Sparkle Revenge of the Cootie Girls. London: Penguin Books, 1997. HIRSCHFELD, Lawrence A. On Acquiring Social Categories: Cognitive Development and Anthropological Wisdom. Man 23:611-638, 1988. - Discovering Linguistic Differences: Domain Specificity and the Young Child's Awareness of Multiple Languages. Human Development 32:223-240, 1989a.

. Rethinking the Acquisition of Kinship Terms. International Journal of Behavioral Development 12:541-568, 1989b.

Discovering Social Difference: The Role of Appearance in the Development of Racial Awareness. Cognitive Psychology 25:317-350, 1993.

54(2):209-252, 1995.

- Do Children Have a Theory of Race? Cognition Race in the Making: Cognition, Culture, and the Child's Construction of Human Kinds. Cambridge, MA: MIT Press, 1996. - The Conceptual Politics of Race: Lessons from Our Children. Ethos 25(1):63-92, 1997.

Making Racial Culture: Children and the Mental Life of a Social Concept. In: Comparative Perspectives on Racism. TER WAI, M. J. A. V., ed. New York: Ashgate, 2000.

102:620-629, 2001.

The Inside Story. American Anthropologist

HIRSCHFELD, Lawrence A., and Susan A. Gelman. Mapping the Mind: Domain Specificity in Cognition and Culture. New York: Cambridge University Press, 1994.

. What Young Children Think about the Relationship Between Language Variation and Social Difference. Cognitive Development 12(2):213-238., 1997.

HOFFMAN, Eva. Lost in Translation. London: Minerva, 1994.

HOLUB, Jane. Ivy Green, Cootie Queen. New York: Troll Communications, 1998.

JACKENDOFF, R. Language of the Mind: Essays on Mental Representation. Cambridge, MA: MIT Press, 1992.

JAMES, Allison, and PROUT, Alan. Constructing and Reconstructing 
Childhood: Contemporary Issues in the Sociological Study of Childhood. New York: Falmer Press, 1990.

JENKS, Chris. Childhood. London: New York: Routledge, 1996.

KALISH, Charles W. Preschoolers' Understanding of Germs as Invisible Mechanisms. Cognitive Development 11(1):83-106, 1996.

KATZ, P. Developmental Foundations of Gender and Racial Attitudes. In: The Child's Construction of Social Inequality. R. Leahy, ed. Pp. 17-54. New York: Academic Press, 1983.

KLSTER, Mary C, and PATTERSON, Charlotte J. Children's Conceptions of the Causes of Illness: Understanding of Contagion and Use of Immanent Justice. Child Development 51(3):839-846, 1980.

LANCY, David. Playing on Mother-Ground. New York: The Gullford Press, 1996.

SLOBIN, Dan Isaac. The Crosslinguistic Study of Language Acquisition. Hillsdale, NJ: L. Eribaum Associates, 1985.

SOLOMON, Gregg E. A., and CASSIMATIS, Nicholas L.. On Facts and Conceptual Systems: Young Children's Integration of Their Understandings of Germs and Contagion. Developmental Psychology 35(1):113-126, 1999.

SPERBER, Dan. Explaining Culture: A Naturalistic Approach. Oxford: Blackwell, 1996.

SPERBER, Dan, and HIRSCHFELD, Lawrence A. Evolution, Cognition, and Culture. In: The MIT Encyclopedia of the Cognitive Sciences. R. Wilson and F. Keil, eds. Cambridge, MA: MIT Press, 1999.

SPRINGER, Ken. Young Children's Understanding of a Biological Basis for Parent-Offspring Relations. Child Development 67(6):2841-2856, 1996.

SPRINGER, Ken, and RUCKEL, Julie. Early Beliefs about the Cause of Illness: Evidence Against Immanent Justice. Cognitive Development 7(4):429-443, 1992.

Challenges of Developing an Ethnography of Children and Childhood. American Anthropologist 100(2):530-531, 1998. STOLER, Ann Laura. Race and the Education of Desire: Foucault's History of Sexuality and the Colonial Order of Things. Durham, NC: Duke University Press, 1995.

STRAUSS, Claudia, and QUINN, Naomi. A Cognitive Theory of Cultural Meaning. New York: Cambridge University Press, 1997.

SULLOWAY, Frank.. Born to Rebel: Birth Order, Family Dynamics, and Creative Lives. New York: Pantheon Books, 1996 
Por que os antropólogos não gostam de crianças?

SUPER, Charles, and HARKNESS, Sara. Anthropological Perspectives on Child Development. San Francisco: Jossey-Bass, 1980.

SUTTON-SMITH, Brian. The Games of New Zealand Children. Berkeley: University of California Press, 1959.

- Toys as Culture. New York: Gardner Press.

Thorne, Barrie. 1993. Gender Play: Girls and Boys in School. New BRUNSWICK, NJ: Rutgers University Press, 1976.

TOREN, Christina. Making History: The Significance of Childhood Cognition for a Comparative Anthropology of Mind. Man 28:461-478, 1993.

WERTSCH, James. Mind as Action. New York: Oxford University Press, 1998.

WHITING, Beatrice. Six Cultures; Studies of Child Rearing. New York: Wiley, 1963.

WHITING, Beatrice, and WHITING, John. Children of Six Cultures: A Psycho-Cultural Analysis. Cambridge, MA: Harvard University Press, 1975.

WHITING, John. Becoming a Kwoma: Teaching and Learning in a New Guinea Tribe. London: Oxford University Press, 1941.

WILLIS, Paul. Learning to Labor: How Working Class Kids Get Working Class Jobs. New York: Columbia University Press, 1981.

WINANT, Howard. Racial Conditions: Politics, Theory, Comparisons. Minneapolis: University of Minnesota Press, 1994. 